\title{
Specific and non-specific clinical presentations in the year before the diagnosis of childhood leukaemia
}

\begin{tabular}{|r|l|}
\hline Journal: & Pediatric Blood \& Cancer \\
\hline Manuscript ID & PBC-16-0009.R1 \\
\hline Wiley - Manuscript type: & Research Article \\
\hline Complete List of Authors: & $\begin{array}{l}\text { Yang, TienYu Owen; University of Oxford, CEU Nuffield Department of } \\
\text { Population Health } \\
\text { Liu, Yen-Lin; Taipei Medical University Hospital, Pediatrics } \\
\text { Huang, Wan-Ting; Taiwan Centers for Disease Control, Office of Preventive } \\
\text { Medicine } \\
\text { Chen, Mei-Huei; National Taiwan University Hospital Yun-Lin Branch, } \\
\text { Department of Pediatrics } \\
\text { Chen, Pau-Chung; National Taiwan University College of Public Health, } \\
\text { Institute of Occupational Medicine and Industrial Hygiene; National Taiwan } \\
\text { University College of Public Health, Department of Public Health; National } \\
\text { Taiwan University College of Medicine and Hospital, Department of } \\
\text { Environmental and Occupational Medicine }\end{array}$ \\
\hline Keywords: & $\begin{array}{l}\text { childhood leukaemia, Epidemiology, early diagnosis, personalised medicine, } \\
\text { cancer screening, electronic health record }\end{array}$ \\
\hline
\end{tabular}




\section{Specific and non-specific clinical presentations}

\section{in the year before the diagnosis of childhood leukaemia}

TienYu Owen Yang ${ }^{1}$, Yen-Lin Liu ${ }^{2,3}$, Wan-Ting Huang ${ }^{4}$, Mei-Huei Chen ${ }^{5}$, Pau-Chung Chen ${ }^{6,7}$

1 Nuffield Department of Population Health, University of Oxford. Richard Doll Building, Old Road Campus, University of Oxford, Oxford OX3 7LF, UK

2 Department of Pediatrics, Taipei Medical University Hospital. No.252, Wu Hsing Street, Taipei City 110, Taiwan

$3 \mathrm{PhD}$ of Translational Medicine Program, National Taiwan University and Academia Sinica;

Department of Pediatrics, National Taiwan University Hospital. No.7, Chung Shan S. Rd. (Zhongshan

S. Rd.), Zhongzheng District, Taipei City 10002, Taiwan

4 Office of Preventive Medicine, Taiwan Centers for Disease Control. No.6, Linsen S. Rd., Jhongjheng District, Taipei City 10050, Taiwan

5 Department of Pediatrics, National Taiwan University Hospital Yun-Lin Branch. No. 9 Xuefu Rd, Huwei Township, Yunlin County 632, Taiwan

6 Institute of Occupational Medicine and Industrial Hygiene, National Taiwan University College of Public Health; Department of Public Health, National Taiwan University College of Public Health. No.17 Xu-Zhou Road, Taipei, 10020 Taiwan 
7 Department of Environmental and Occupational Medicine, National Taiwan University College of Medicine and Hospital. No.7, Chung Shan S. Rd. (Zhongshan S. Rd.), Zhongzheng District, Taipei City 10002, Taiwan

Correspondence:

TienYu Owen Yang

CEU Richard Doll Building, Old Road Campus, Oxford, UK OX37LF

TEL: +44 1865289600

FAX: +441865289610

E-mail: tienyu.owen.yang@gmail.com

Text word count 2765;

Abstract word count 248;

Brief running title: presentations of childhood leukaemia

Key words: childhood leukaemia, epidemiology, early diagnosis, personalised medicine, cancer screening, electronic health record

Tables: 1

Figures: 3

\begin{tabular}{|l|l|}
\hline Abbreviations \\
\hline CI & Confidence interval \\
\hline ICD-9 & International Classification of Diseases, Revision 9 \\
\hline NHIRD & Taiwan National Health Insurance Research Databases \\
\hline OR & Odds ratio \\
\hline
\end{tabular}




\section{ABSTRACT}

\section{Introduction}

Clinical presentations of childhood leukaemia have been reported in case-only studies. The timing when these presentations start to occur prior to diagnosis is less clear.

\section{Methods}

In this nested case-control study, 1,025 and 334 children with lymphoid and myeloid leukaemia, respectively, were matched (1:30) to population-based controls by sex, region, and year of birth. An index date was assigned for each control when the matched case was diagnosed. Healthcare access records of cases and controls in the year before the index date were extracted.

\section{Results}

Children with lymphoid leukaemia started to visit doctors more often at least two months before leukaemia diagnosis $(\mathrm{p}<0.05)$. Various presentations were recorded in these visits: rates of haematological presentations, musculoskeletal presentations, and injuries started to increase significantly at least three months before diagnosis; rates of respiratory, gastrointestinal, and urinary tract presentations did not increase significantly until the last month. The findings for myeloid lymphoma were less clear, but children appeared to visit doctors more often at least four months before diagnosis, and the rate of haematological presentations also started to increase at least four months before leukaemia diagnosis. Although haematological presentations were most strongly associated with undiagnosed leukaemia (odds ratio $>290$ in the last month), the majority ( $>96 \%$ ) of children with haematological presentations did not have leukaemia if they had not been diagnosed in their first visit.

\section{Conclusion}


We described a clinical picture in the year before leukaemia diagnosis. These findings revealed ongoing difficulties in early diagnosis of childhood leukaemia in healthcare settings. 


\section{INTRODUCTION}

Clinical studies have reported some presentations before or at the time of leukaemia diagnosis, such as fever, anaemia, bleeding, or musculoskeletal discomfort.[1-8] Researchers have also attempted to summarise the duration between initial presentations and leukaemia diagnosis in case series. [9-11] However, many of these presentations are not specific and can be seen among children with leukaemia as well as children in the general population, and the extent to which these presentations were associated with leukaemia is unclear.

In a controlled study, either matched controls [12] or self-control studies [13], the association between a presentation and its underlying cause can be investigated, and reporting bias can be reduced if information of presentations can be recorded prior to leukaemia diagnosis. In Taiwan, presentations of all healthcare visits are recorded by physicians and stored electronically in the database of the National Health Insurance programme. For children with leukaemia, records of healthcare visits before leukaemia diagnosis provide physicians' clinical impressions at the time of each visit, unbiased by the knowledge of underlying leukaemia. With a high volume of healthcare access, Taiwanese children visits physicians very frequently, and it is reported nearly 6 in every 10 children aged 0-4 years visit physicians each month.[14] This allows minor and major presentations to be seen and recorded by physicians. Here we report a nested case-control study on the specific and non-specific clinical presentations in the year before lymphoid and myeloid leukaemia diagnosis in Taiwan.

\section{METHODS}

The Taiwan National Health Insurance Research Databases (NHIRD) have been described elsewhere.[15] Two NHIRD databases were used in this study, the longitudinal database 2005 and the catastrophic illness database 1998-2008. In brief, more than 99\% of the Taiwanese population has been covered by the National Health Insurance since its establishment in late 1990s, and the NHIRD longitudinal database 2005 took a 1-million representative random sample of Taiwanese population ( $\sim \%$ of 23 million) in 2005 , and extracted all primary and secondary healthcare information for this 
sample for research use. From 2000 all diagnoses were coded according to the International Classification of Diseases, Revision 9 (ICD-9). The second database, the NHIRD catastrophic database, is also a longitudinal database, which includes any Taiwanese who had ever had a catastrophic illness (including childhood leukaemia), and then extracted all primary and secondary healthcare information for these people for research use. Those recorded in the catastrophic database were eligible for substantial reimbursement, and diagnoses were verified by specialists after reviewing clinical evidence.

Because the NHIRD longitudinal database 2005 is a representative sample of the entire Taiwanese population, and the NHIRD catastrophic database contained all leukaemia cases in Taiwan, the combination of the two databases during the overlapping period is effectively a nested case-control sample in the entire Taiwanese population. From the catastrophic illnesses database, therefore, we identified all lymphoid leukaemia (ICD-9 204) and myeloid leukaemia (205) first diagnosed between the $2^{\text {nd }}$ and the $16^{\text {th }}$ birthday in 2001-2008. Up to 30 non-duplicated children were selected as matched controls from the NHIRD longitudinal 2005 database for each case by calendar year of birth, sex, and five geographical regions [14], and an index date was assigned for each control on the date when the matched case was diagnosed. Healthcare access records of all cases and controls in the year before the index date were extracted.

\section{Data analysis}

We estimated the rates (proportions) of children accessing healthcare services (clinic visits, emergency visits, or hospital admissions) by time to the index date in 30-day periods, i.e. 1-30, 31 $60, \ldots$, up to 331-360 days to the index date. Rates were estimated using mixed-effect logistic model, including two fixed effect terms, an 2-by-12 interaction term by a case-control identifier and by time to the index date (1-12 months), and a term of age on the index date (2-4, 5-8 and 9+ years), and one random effect term stratified by case-control group. This was analysed using melogit and margins command in STATA 14.0. 
We then estimated the relative rates of six presentation-specific healthcare accesses by time to the index date, including haematological presentations (ICD-9 280-289), respiratory presentations (460466, 477, 480-486), gastrointestinal presentations (535-537, 564), urinary tract presentations (590, 595, 597, 599), musculoskeletal presentations (710-739), and injuries (800-848, 910-929). These presentations were selected and defined based on the findings of a data-informed process, a case-only analysis which screened for ICD-9 3-digit codes that were increasingly recorded shortly before leukaemia diagnosis (1-180 days versus 181-360 days before diagnosis, see Appendix pp2-3). Codes identified from this analysis and other clinically related codes were then grouped into the six presentation categories. Relative rates were estimated using the aforementioned mixed effect logistic model.

In each analysis the rate 331-360 days (i.e. 12 months) before the index date among controls was used as a reference category, but group- and time-specific odds ratios were calculated -- confidence intervals were re-assigned to each group-time category including the reference group using floating absolute risks [16] method, so that any two categories could be compared independently even if neither of them were the reference category.

To describe a more comprehensive clinical picture in the year before leukaemia diagnosis, the rates of general presentations were presented in magnitude of statistical significance, odds ratios (ORs), and in absolute rates. A cut-off point of $\mathrm{p}=0.05$ divided by numbers of tests was used for nominal significance. Exact percentages $<1 \%$ among cases and $<0.1 \%$ among controls are not shown to comply with data regulations.

\section{Data access and ethics considerations}

Pseudonymised databases released from authorities for research use were used in this study.

Databases should be accessed via Taiwan Ministry of Health and Welfare

(http://www.mohw.gov.tw/EN/Ministry/). Background information and data protection of NHIRD can be found on NHIRD website.[17] 


\section{RESULTS}

We identified 1,025 and 334 children with lymphoid and myeloid leukaemia, respectively, diagnosed between age 2 and 16 years during 2001-2008 in Taiwan. Characteristics of cases and controls are shown in Table I. The median age of diagnosis was 6.1 (interquartile range [IQR] 3.8-10.2) years for lymphoid leukaemia and 9.3 (IQR 5.7-12.9) years for myeloid leukaemia. Proportions of children accessing healthcare services by time to leukaemia diagnosis (in 30-day periods) are shown in Figure 1, and the corresponding numbers are listed in Appendix pp4-5. Consistent with our previous report [14], the baseline rate of young children accessing healthcare services was very high -- around every 1 in 2 children had visited a doctor during any 30-day period (controls, Figure 1 in grey). Compared to matched controls, children with undiagnosed lymphoid leukaemia started to access healthcare services more often since 31-60 days (the second month) before leukaemia diagnosis $(\mathrm{p}<0.05)$. The proportion continued to increase afterwards, and in the last 30 days before leukaemia diagnosis $92 \%$ children were estimated to have accessed health care, compared to only $57 \%$ among matched controls.

Children with undiagnosed myeloid leukaemia were found to access healthcare services more often since 91-120 days (the fourth month) before leukaemia diagnosis $(\mathrm{p}<0.05)$. The proportion also continued to increase towards the last 30 days before leukaemia diagnosis, when $90 \%$ children were estimated to have accessed health care, compared to $49 \%$ among matched controls.

The majority of healthcare access among children with leukaemia was via primary care services (clinics, outpatient clinics, or emergency that did not lead to hospital admission), and this remains true even in the last 30 days before leukaemia diagnosis: 1,248 (92\%) children with lymphoid or myeloid leukaemia accessed primary care in the last 30 days before leukaemia diagnosis, compared to only 62 (5\%) children among them accessed secondary care (i.e. hospital admission).

Presentation-specific healthcare access in the year before the diagnosis of lymphoid leukaemia

Figure 2 shows presentation-specific healthcare access in the year before the diagnosis of lymphoid leukaemia. The corresponding numbers are listed in Appendix pp6-11. Among the six general presentations examined, rates of haematological presentations, musculoskeletal presentations, and 
injuries were the earliest to increase significantly compared to controls, found to increase since the third month (61-90 days) before the date of lymphoid leukaemia diagnosis (Figure 2A). This was followed by increasing rates of respiratory, gastrointestinal and urinary tract presentations, found to be statistically significant since the second month (31-60 days) before leukaemia diagnosis. Relative rates of all six presentations continued to increase until the date of diagnosis (Figure 2B), but the absolute rates did not change substantially until the last month (Figure 2C). Moreover, high relative rates did not always correspond to high absolute rates. For example, by the last month before lymphoid leukaemia diagnosis, the largest absolute difference between cases and controls was seen in respiratory presentations ( $75 \%$ in cases versus $43 \%$ in controls, $22 \%$ difference, $\mathrm{OR}=4.2$ ), larger than the absolute difference seen in haematological presentations ( $17 \%$ in cases versus $<0.1 \%$ in controls, $\mathrm{OR}=292$ ).

Presentation-specific healthcare access in the year before the diagnosis of myeloid leukaemia

Figure 3 shows presentation-specific healthcare access in the year before the diagnosis of myeloid leukaemia. The corresponding numbers are listed in Appendix pp12-17. Among the six general presentations examined, the rate of haematological presentations was the earliest to increase significantly, found to increase since the fourth month (91-120 days) before the date of myeloid leukaemia diagnosis (Figure 3A). There were possible significant increases in rates of respiratory and musculoskeletal presentations 2 months before diagnosis, but the confidence intervals were relatively wide (numbers are listed in Appendix pp13 and 16). As expected, relative rates of most presentations continued to increase until the date of diagnosis of myeloid leukaemia (Figure 3B), but the absolute rate did not change substantially until the last month (Figure 3C). In the last month before lymphoid leukaemia diagnosis, the largest absolute difference between cases and controls was seen in respiratory presentations with $69 \%$ in cases versus $33 \%$ in controls ( $36 \%$ difference, $\mathrm{OR}=4.7)$, larger than the absolute difference seen in haematological presentations despite the large odds ratio $(16 \%$ in cases versus $<0.1 \%$ in controls, $\mathrm{OR}=376$ ). 


\section{DISCUSSION}

In this population-based report of 1,359 Taiwanese children with leukaemia, physicians' clinical impressions during each visit were recorded prospectively in the year before leukaemia diagnosis. Using these records, we found evidence suggesting children started to visit doctors more often at least two months before lymphoid leukaemia diagnosis and four months before myeloid leukaemia diagnosis, and with various clinical presentations. Not all presentations occurred at the same time. The rates of haematological presentations, of musculoskeletal presentations, and of injuries seemed to increase significantly since the third month before the diagnosis of lymphoid leukaemia, and the rate of haematological presentations seemed to increase significantly since the four month before the diagnosis of myeloid leukaemia.

The presentations that were increasingly seen by physicians in the year before leukaemia diagnosis were most likely to be caused by underlying undiagnosed leukaemia. The timing of various presentations may be related to the burden of leukemic cells: the leukaemia burden at an early stage of leukaemia is small, and may only affect the haematological system or surrounding osteoarticular tissues. Previous studies, primarily case-only reports, has also suggested haematological and musculoskeletal presentations as signs of leukaemia [1-8], and to our knowledge our report is the first to quantify these associations. Additionally, we demonstrated the timing of these and other less specific presentations, including respiratory, gastrointestinal, and urinary tract presentations, and injuries.

These findings revealed ongoing difficulties to use specific symptoms as guides for early diagnosis. For example, the baseline rate of haematological presentations among controls in this report was small $(\sim 0.1 \%)$ but still much higher than the incidence of childhood leukaemia (reported at around 40 per million child-year, or $0.004 \%$ in Taiwan).[18] This corresponds to a false negative rate of $\sim 4 \%$ among children recorded with haematological presentations after a physician visit, during which some basic, minimally invasive laboratory tests may have already been requested. So far there is lack of safe and accurate detecting methods to further reduce this false native rate. Moreover, although there is a high 
association between haematological presentations and leukaemia at near the time of diagnosis $(>200$ folds in the last month for both lymphoid and myeloid leukaemia), the odds ratio was substantially lower three months ago (5-10 folds), and less than 2\% of children with underlying leukaemia had been seen with haematological presentations at this time. Therefore, being able to reduce the aforementioned $\sim 4 \%$ false negative rate to $0 \%$, if possible, may bring the diagnosis date 3 months forward only for $2 \%$ of children with leukaemia. In all, our findings have depicted a collective clinical picture in the year before leukaemia diagnosis, which however seemed to suggest a limited extent to which leukaemia can be earlier diagnosed in the clinical setting.

Indeed, most improvement in the prognosis of childhood leukaemia in past decades has generally been attributed to successful treatment and risk stratification at the time of diagnosis, $[19,20]$ and currently there is no strong evidence suggesting further benefits in early diagnosis. Design of any prognosis-improving intervention involving early diagnosis will probably require more integrated assessment involving various risk-reduction strategies from early diagnosis to long-term survival.

Compared to previous case-only studies [9-11] in which confounding by time-related factors such as age or season cannot be ruled out, we were able to demonstrate relative rates of presentations compared to both case baseline and matched controls. The stable rates of healthcare access over time in the matched controls suggested that our estimates were unlikely to be largely confounded by timerelated factors. The fact that cases and controls had similar rates of presentations at baseline (12 months before diagnosis) suggested there was no substantial difference between cases and controls long before leukaemia diagnosis. Interestingly, our finding of increasing rates of healthcare access since around 3 months before leukaemia diagnosis ( 2 months before lymphoid leukaemia and 4 months before myeloid leukaemia) is similar to a report in Denmark (3 months before leukaemia diagnosis).[12] This coincidence may suggest some consistency between the two countries, and our report additionally depicted presentation-specific clinical pictures in the year before diagnosis.

Although the baseline healthcare access rate in our report was similar between cases and controls 12 months before the index date, we could not exclude the possibility of a difference at a longer duration 
before leukaemia diagnosis. In population mixing hypothesis $[21,22]$ or delayed infection hypothesis $[23,24]$, risk of leukaemia is thought to be related to the interaction between perinatal infectious exposures and immune responses. Since our analyses were focused only on the year before leukaemia diagnosis, these immune hypotheses were not tested. We also ought to clarify that lymphoid and myeloid leukaemia were not directly compared in this study, as they were not matched in the same comparison group. Each case was compared to its matched controls, and the collective case-control profile of lymphoid leukaemia by age, sex, region, and time of diagnosis was different from the casecontrol profile of myeloid leukaemia. It is therefore not appropriate to directly infer any difference in presentations or timing of presentations in our study between the two types. Some apparent differences may also be artefacts related to a smaller number of myeloid leukaemia in this study, causing less stable findings both in statistical significance and in the magnitude of estimates.

This is the first controlled study and the largest study (1,359 childhood leukaemias) so far where presentation-specific healthcare access can be quantified and reported by time to the date of leukaemia diagnosis. For a rare disease such as childhood leukaemia, the prospectively recorded information would not have been available without routine collection through healthcare service, and would not have been statistically powerful without such high background rates of doctor visits in Taiwan, allowing many events to have been captured in the database. However, interpretation of results is inevitably limited by the nature of this type of data. Because these findings were restricted to ICD-9 codes, detailed information such as clinical history, physical examination, or laboratory tests was not available, although the standardised coding system did reveal physicians' impressions after reasonable clinical investigations under contemporary general practice. Our categories of presentations were informed by a data-driven process that mimicked genetic association studies. Similar to genetic association studies where statistical signals are treated as association markers of biological pathways subjective to various interpretations, individual statistical signals in this study were seen as association markers of broader underlying presentations, and selection of the six presentations can be subject to interpretation bias. Chance findings after multiple comparisons or confounding through unknown factors also remained possible. 
In all, we used recorded healthcare data to describe a clinical picture in the year before the diagnosis of childhood leukaemia, and this is the first report to quantify the relative rates of various presentations. These quantified findings revealed ongoing difficulties in earlier diagnosis of leukaemia in clinical settings under the contemporary practice.

\section{CONFLICT OF INTEREST}

The study is funded internally. All authors and affiliations declare no conflict of interest.

\section{REFERENCE}

1. Brix N, Rosthoj S. Bone marrow involvement is not manifest in the early stages of childhood acute lymphoblastic leukaemia. Danish medical journal 2014:61(8):A4883.

2. Zombori L, Kovacs G, Csoka M, Derfalvi B. Rheumatic symptoms in childhood leukaemia and lymphoma-a ten-year retrospective study. Pediatric rheumatology online journal 2013:11:20.

3. Teo WY, Chan MY, Ng KC, Tan AM. Bony presentations of childhood haematological malignancy to the emergency room. J Paediatr Child Health 2012:48(4):311-316.

4. Karimi M, Mehrabani D, Yarmohammadi H, Jahromi FS. The prevalence of signs and symptoms of childhood leukemia and lymphoma in Fars Province, Southern Iran. Cancer detection and prevention 2008:32(2):178-183.

5. Biswas S, Chakrabarti S, Chakraborty J, Paul PC, Konar A, Das S. Childhood acute leukemia in West Bengal, India with an emphasis on uncommon clinical features. Asian Pacific journal of cancer prevention : APJCP 2009:10(5):903-906.

6. Bhatnagar SK, Chandra J, Narayan S, Sharma S, Singh V, Dutta AK. Pancytopenia in children: etiological profile. Journal of tropical pediatrics 2005:51(4):236-239.

7. Aysun S, Topcu M, Gunay M, Topaloglu H. Neurologic features as initial presentations of childhood malignancies. Pediatric neurology 1994:10(1):40-43.

8. Brix N, Rosthoj S, Herlin T, Hasle H. Arthritis as presenting manifestation of acute lymphoblastic leukaemia in children. Arch Dis Child 2015:100(9):821-825.

9. Lethaby CD, Picton S, Kinsey SE, Phillips R, van Laar M, Feltbower RG. A systematic review of time to diagnosis in children and young adults with cancer. Arch Dis Child 2013:98(5):349355.

10. Roskin J, Diviney J, Nanduri V. Presentation of childhood cancers to a paediatric shared care unit. Arch Dis Child 2015:100(12):1131-1135.

11. Dang-Tan T, Trottier H, Mery LS, Morrison HI, Barr RD, Greenberg ML, Franco EL. Delays in diagnosis and treatment among children and adolescents with cancer in Canada. Pediatr Blood Cancer 2008:51(4):468-474.

12. Ahrensberg JM, Fenger-Gron M, Vedsted P. Use of primary care during the year before childhood cancer diagnosis: a nationwide population-based matched comparative study. PLoS One 2013:8(3):e59098. 
13. Chu TP, Shah A, Walker D, Coleman MP. Pattern of symptoms and signs of primary intracranial tumours in children and young adults: a record linkage study. Arch Dis Child 2015.

14. Yang TYO, Huang W-T, Chen M-H, Chen P-C. Seasonal synchrony in incidences of common infectious diseases in early childhood among neighbouring regions. International Journal of Infectious Diseases 2014:28:214.

15. Hsing AW, loannidis JP. Nationwide Population Science: Lessons From the Taiwan National Health Insurance Research Database. JAMA internal medicine 2015:175(9):1527.

16. Plummer M. Improved estimates of floating absolute risk. Stat Med 2004:23(1):93-104.

17. National Health Insurance Research Database: Data Protection. 06 November. <http://nhird.nhri.org.tw/en/Data Protection.html>. Accessed 201506 November.

18. Liu YL, Lo WC, Chiang CJ, Yang YW, Lu MY, Hsu WM, Ho WL, Li MJ, Miser JS, Lin DT, Lai MS. Incidence of cancer in children aged 0-14 years in Taiwan, 1996-2010. Cancer Epidemiol 2015:39(1):21-28.

19. Armstrong GT, Chen Y, Yasui Y, Leisenring W, Gibson TM, Mertens AC, Stovall M, Oeffinger KC, Bhatia S, Krull KR, Nathan PC, Neglia JP, Green DM, Hudson MM, Robison LL. Reduction in Late Mortality among 5-Year Survivors of Childhood Cancer. N Engl J Med 2016.

20. Robison LL, Hudson MM. Survivors of childhood and adolescent cancer: life-long risks and responsibilities. Nature reviews Cancer 2014:14(1):61-70.

21. Kinlen LJ. Epidemiological evidence for an infective basis in childhood leukaemia. Br J Cancer 1995:71(1):1-5.

22. Kinlen L. Evidence for an infective cause of childhood leukaemia: comparison of a Scottish new town with nuclear reprocessing sites in Britain. Lancet 1988:2(8624):1323-1327.

23. Greaves M. Infection, immune responses and the aetiology of childhood leukaemia. Nature reviews Cancer 2006:6(3):193-203.

24. Greaves MF. Speculations on the cause of childhood acute lymphoblastic leukemia. Leukemia 1988:2(2):120-125. 


\section{FIGURE LEGENDS}

\section{Figure 1.}

Standardised proportions and $95 \%$ confidence intervals of children accessing healthcare services each month (30-day periods) counting backwards from the date of leukaemia diagnosis among cases (black) or from the index date among matched controls (grey).

Figure 2. Presentations increasingly recorded in the year before the date of lymphoid leukaemia diagnosis.

Figure 2A shows levels of statistical significance for increasingly recorded general presentations in each 30-day period counting back from the date of lymphoid leukaemia diagnosis compared to matched controls (see methods for matching details). Asterisks suggest nominal statistical significance $(\mathrm{p}<0.05)$ after correction for multiple comparisons. Figure $2 \mathrm{~B}$ shows the extent to which general presentations were increasingly recorded, expressed in natural log of odds ratios, i.e. $\ln (\mathrm{OR})$. Figure 2C summarises the observed proportions of cases (red) and controls (blue) recorded to have six general presentations at the twelfth, third, and the last month before the date of leukaemia diagnosis (in cases) or the matched index date (in controls).

Figure 3. Presentations increasingly recorded in the year before the date of myeloid leukaemia diagnosis.

Figure 3A shows levels of statistical significance for increasingly recorded general presentations in each 30-day period counting back from the date of lymphoid leukaemia diagnosis compared to matched controls (see methods for matching details). Asterisks suggest nominal statistical significance $(\mathrm{p}<0.05)$ after correction for multiple comparisons. Figure 3B shows the extent to which general presentations were increasingly recorded, expressed in natural log of odds ratios, i.e. $\ln (\mathrm{OR})$. Figure $3 \mathrm{C}$ summarises the observed proportions of cases (red) and controls (blue) recorded to have six general presentations at the twelfth, third, and the last month before the date of leukaemia diagnosis (in cases) or the matched index date (in controls). 


\section{LEGENDS FOR SUPPLEMENTARY FILES}

\begin{tabular}{ll}
\hline File name & Content \\
\hline Appendix_20160312Owen.pdf & Main appendix to be published online. The \\
& index is listed on Page 1 of the appendix file. \\
SupplementaryforReviewOnly_20160312Owen.docx & STATA OUTPUT corresponding to \\
& REVIEWER \#2 MAJOR CONCERN \#1 for \\
& reviewer(s) only and not to be published.
\end{tabular}


Table I. Characteristics of cases and matched controls

\begin{tabular}{|c|c|c|c|c|}
\hline & \multicolumn{2}{|c|}{ Lymphoid leukaemia } & \multicolumn{2}{|c|}{ Myeloid leukaemia } \\
\hline & Cases & Controls $^{1}$ & Cases & Controls $^{1}$ \\
\hline $\mathrm{n}$ & 1025 & 24648 & 334 & 8850 \\
\hline Age at start of follow up (median, $[\mathrm{IQR}]^{2}$ ) & $\begin{array}{c}2.4[0.0,6.2] \\
6.1[3.8\end{array}$ & $2.6[0.0,6.3]$ & $5.0[0.5,8.9]$ & $5.4[1.9,8.9]$ \\
\hline Age at end of follow up (median, $[\mathrm{IQR}]^{2}$ ) & $10.2]$ & $5.9[3.7,10.4]$ & $9.3[5.7,12.9]$ & $10.0[6.3,13.1]$ \\
\hline Male (\%) & 58.6 & 57.2 & 53.9 & 53.9 \\
\hline \multicolumn{5}{|l|}{ Geographic region (\%) } \\
\hline Northern & 53.8 & 53.2 & 55.1 & 54.0 \\
\hline Central & 15.7 & 16.3 & 18.3 & 18.4 \\
\hline Southern & 26.0 & 26.0 & 23.4 & 23.6 \\
\hline Others & 4.6 & 4.5 & 3.3 & 3.9 \\
\hline
\end{tabular}

${ }^{1}$ Cases and controls were matched exactly by year of birth, week of leukaemia diagnosis, sex and geographic region. The apparent imbalance between all cases and all controls is due to different case-control ratios across the casecontrol strata. ${ }^{2}$ IQR: Interquartile range (the 25 th and 75 th percentiles) 


\section{Lymphoid leukaemia}

Percentage of children accessing healthcare service each month

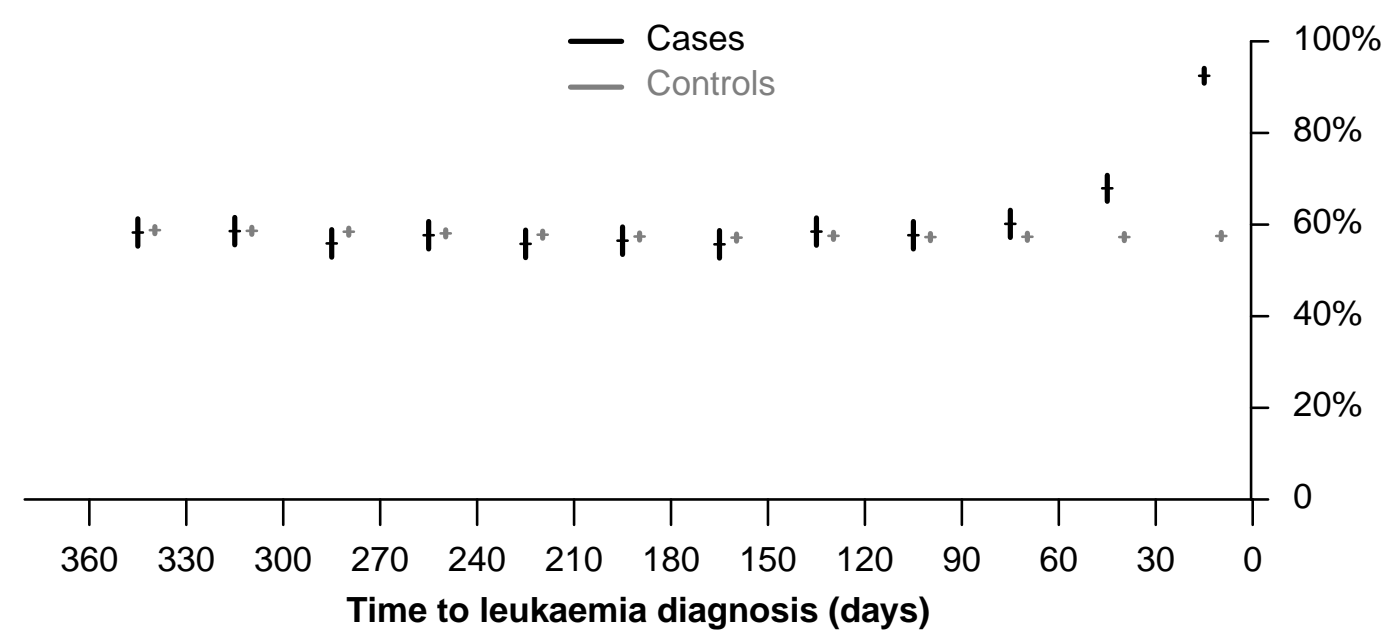

Myeloid leukaemia

Percentage of children accessing healthcare service each month

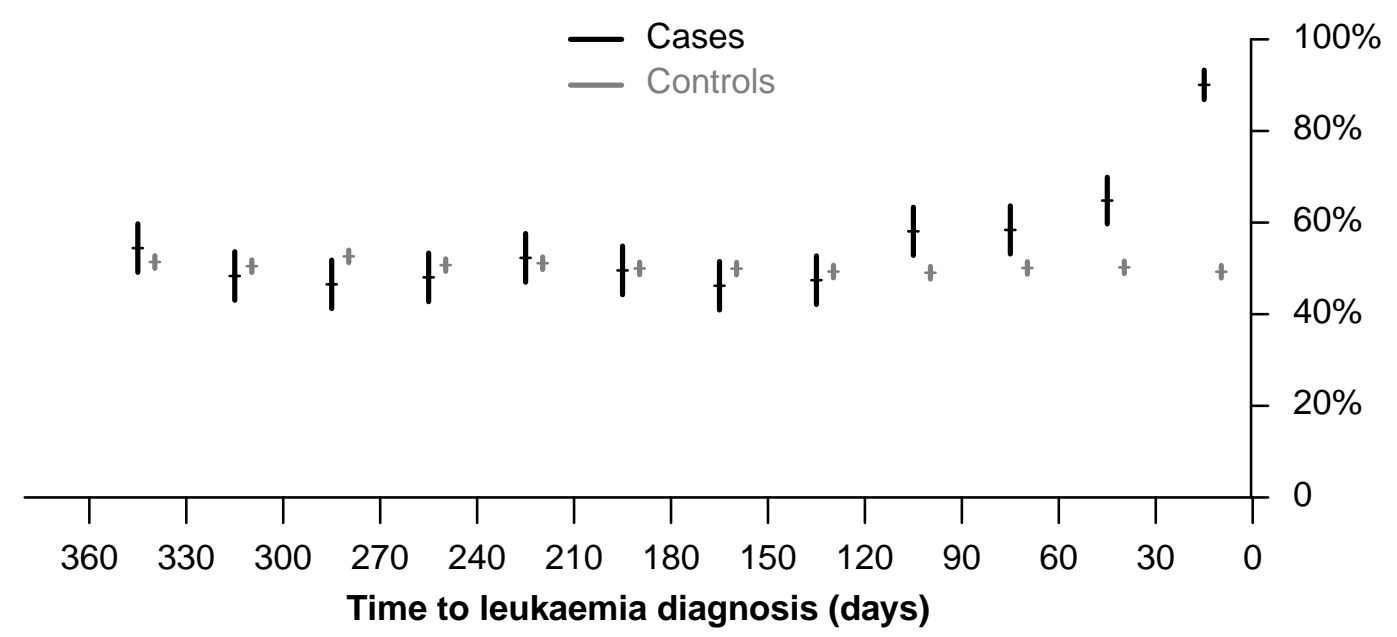


A

\section{Lymphoid leukaemia}

Haematological 280-289

\section{Respiratory}

460-466,477,480-486

Gastrointestinal 535-537,564

Urinary Tract

$590,595,597,599$

Musculoskeletal

710-739

\section{Injuries}

800-848,910-929

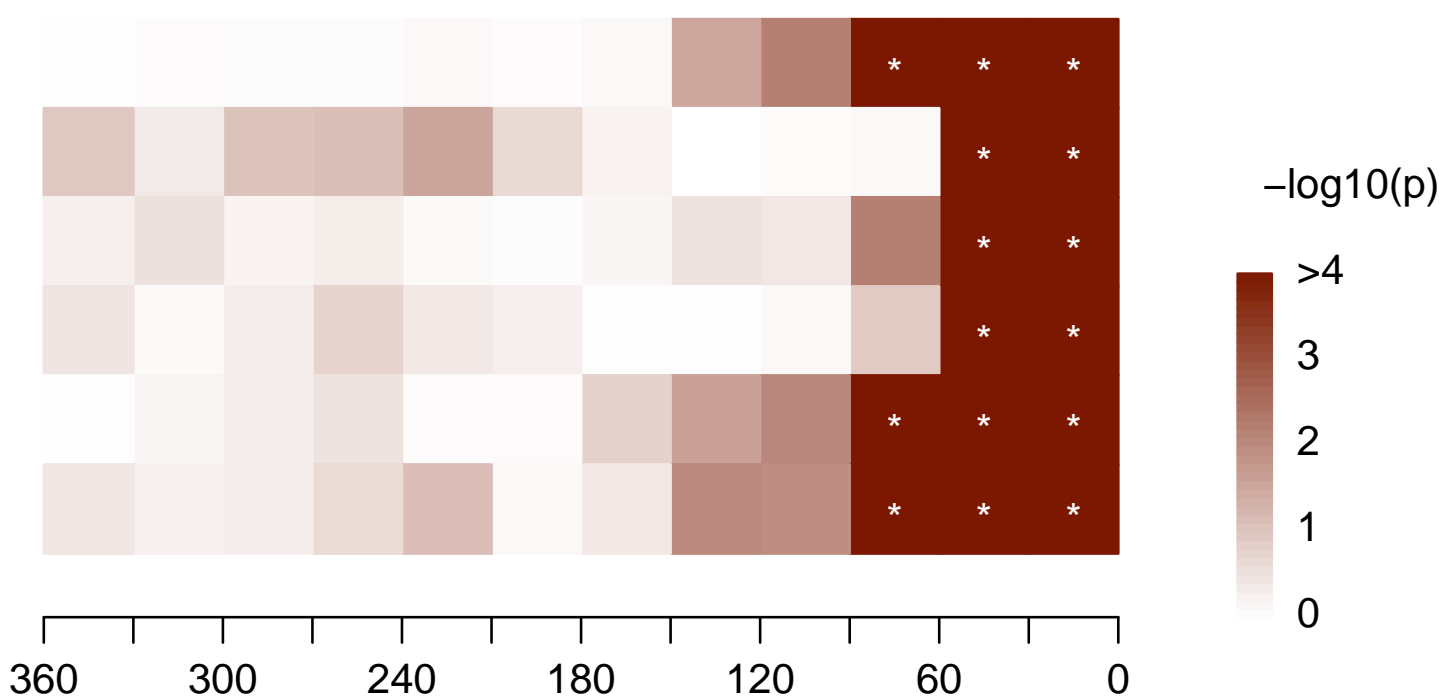

Time to leukaemia diagnosis (days)

B

Haematological 280-289

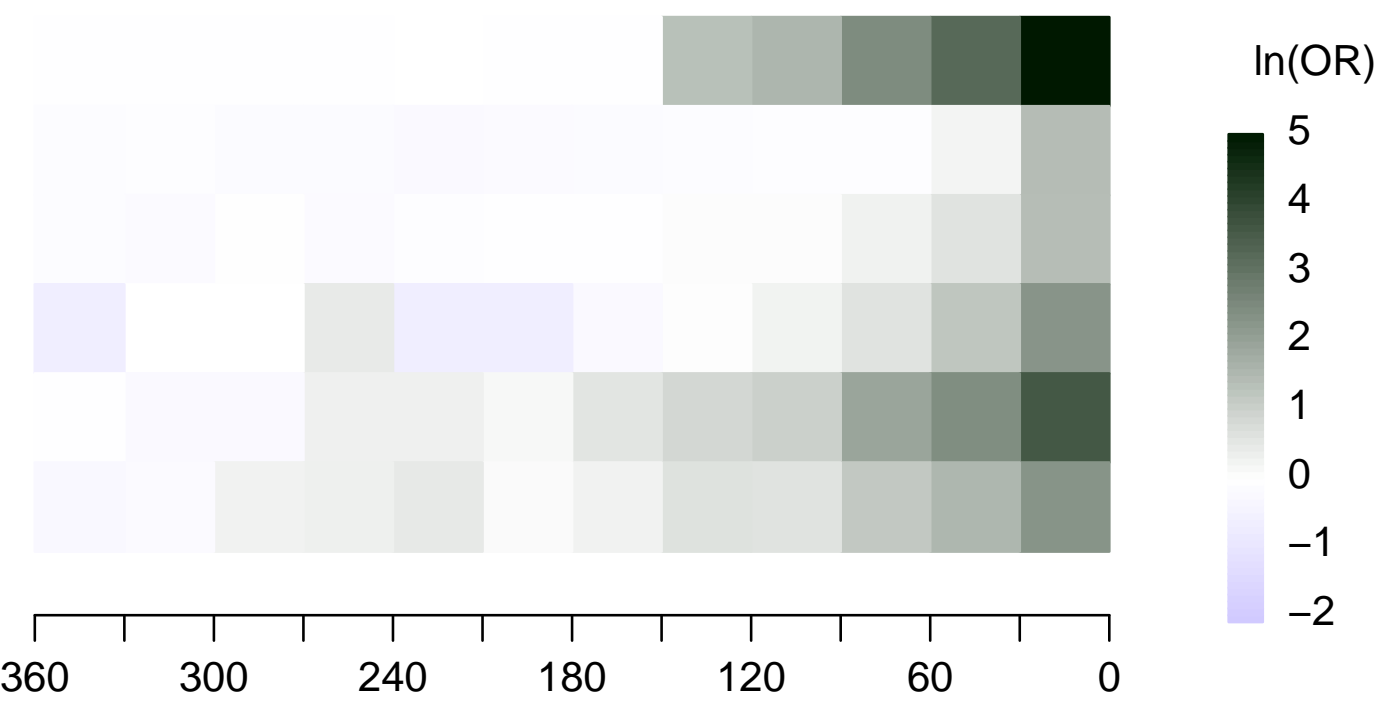

$\ln (\mathrm{OR})$

Respiratory

460-466,477,480-486

Gastrointestinal

535-537,564

Urinary Tract

590,595,597,599

Musculoskeletal

710-739

Injuries

800-848,910-929

Time to leukaemia diagnosis (days)

0

Cases
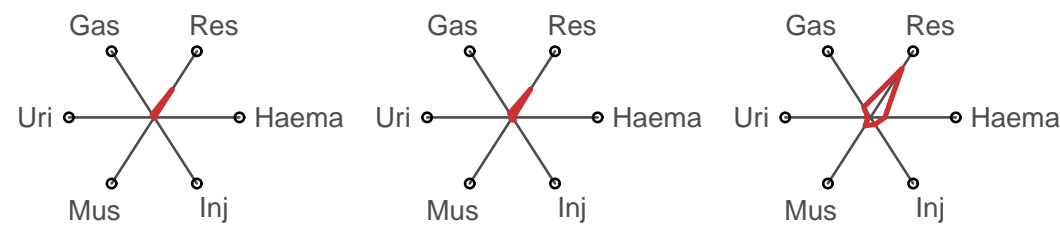

Controls
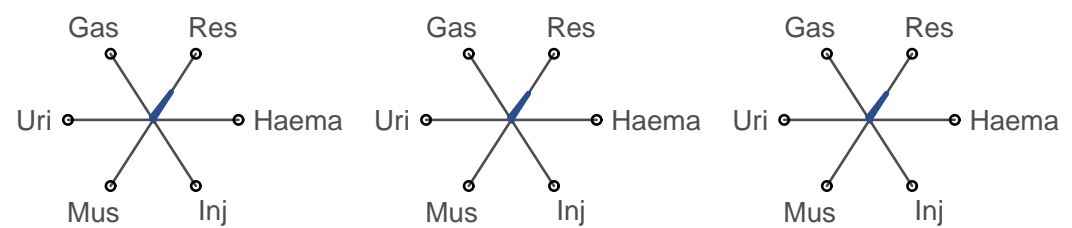

331-360 dayns Wiley \& s61-90 days

1-30 days 


\section{Myeloid leukaemia}

A

Haematological 280-289

Respiratory

460-466,477,480-486

Gastrointestinal 535-537,564

Urinary Tract

$590,595,597,599$

Musculoskeletal

710-739

Injuries

800-848,910-929

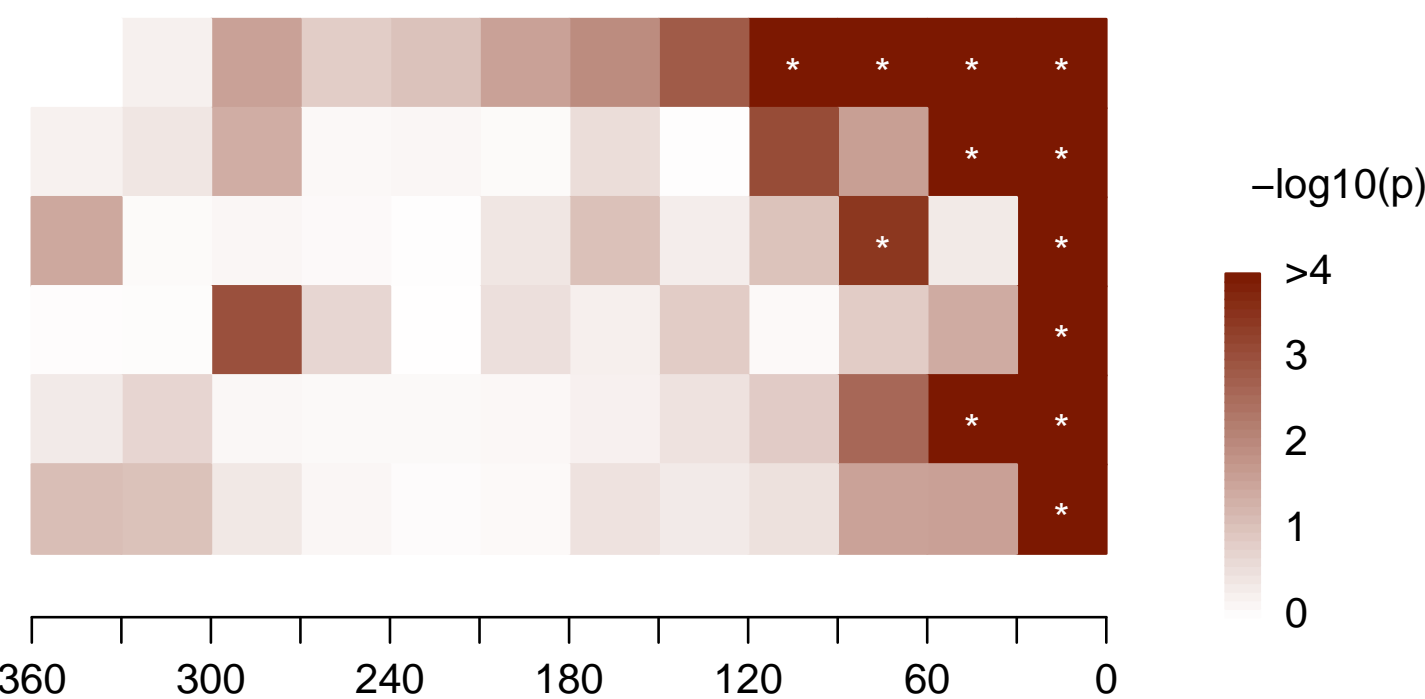

Time to leukaemia diagnosis (days)

B

Haematological 280-289

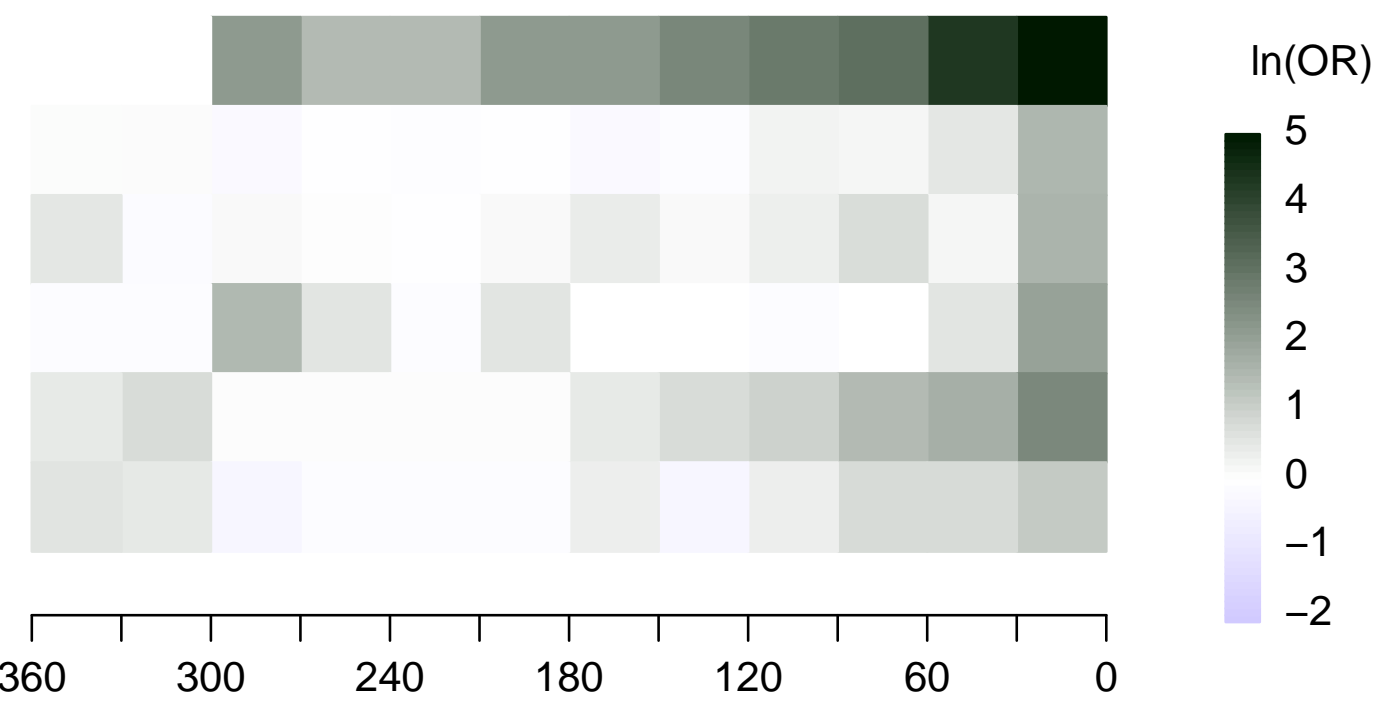

$\ln (\mathrm{OR})$

Respiratory

460-466,477,480-486

Gastrointestinal

535-537,564

Urinary Tract

590,595,597,599

Musculoskeletal

710-739

Injuries

800-848,910-929

Time to leukaemia diagnosis (days)

C

Cases
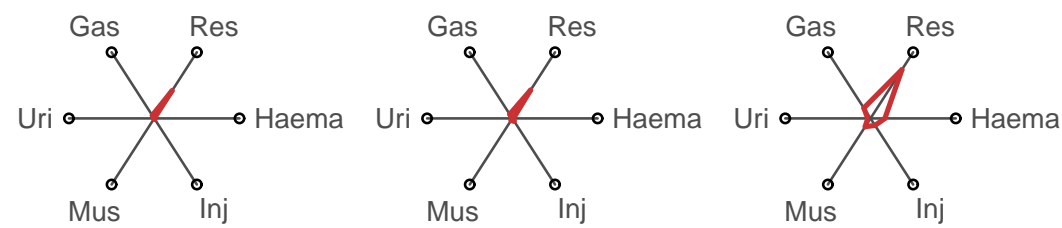

Controls
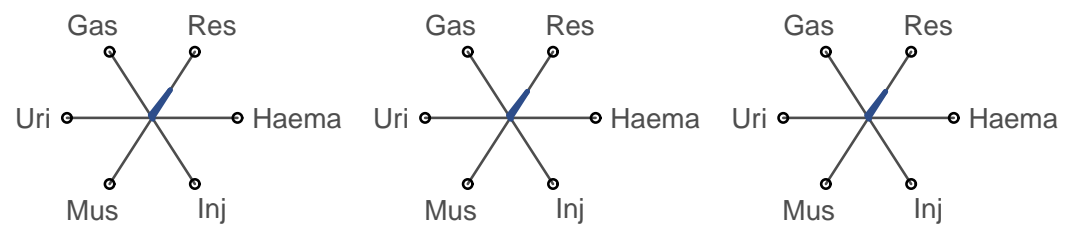

331-360 dagys Wiley \& s81-90 days

1-30 days 


\title{
Specific and non-specific clinical presentations
}

\author{
in the year before the diagnosis of childhood leukaemia
}

TienYu Owen Yang, Yen-Lin Liu, Wan-Ting Huang, Mei-Huei Chen, Pau-Chung Chen

\section{Appendix}

Appendix pp2-3 Figure. Presentations increasingly recorded 1-180 days before the date of leukaemia diagnosis compared to 181-360 days before the date of leukaemia diagnosis.

Appendix pp4-5 Table: Numbers corresponding to Figure 1

Adjusted proportions and 95\% confidence intervals of children accessing healthcare services each month counting backwards from the date of leukaemia diagnosis among cases or from the index date among matched controls.

Appendix pp6-11 Table: Numbers corresponding to Figure 2

Presentations increasingly recorded in the year before the date of lymphoid leukaemia diagnosis.

Appendix pp6-11 Table: Numbers corresponding to Figure 3

Presentations increasingly recorded in the year before the date of myeloid leukaemia diagnosis. 
Figure (Next page). Presentations increasingly recorded 1-180 days before the date of leukaemia diagnosis compared to 181-360 days before the date of leukaemia diagnosis.

By 3-digit codes according to the International Classification of Diseases, Revision 9 (ICD-9), records of presentation codes were compared between 1-180 days and 181-360 days before the date of lymphoid or myeloid leukaemia diagnosis among 1359 leukaemia cases. Numbers of records between the two periods (1-180 and 181-360 days before diagnosis) were compared within each child using conditional logistic model. Dash line shows the cut-off point of $p$ value above which increase (closed squares) or decrease (open squares) is considered statistically significant ( $p<0.05$ after corrected for multiple comparisons). Numbers and statistics for presentations that were increasingly recorded are listed in the table below. 


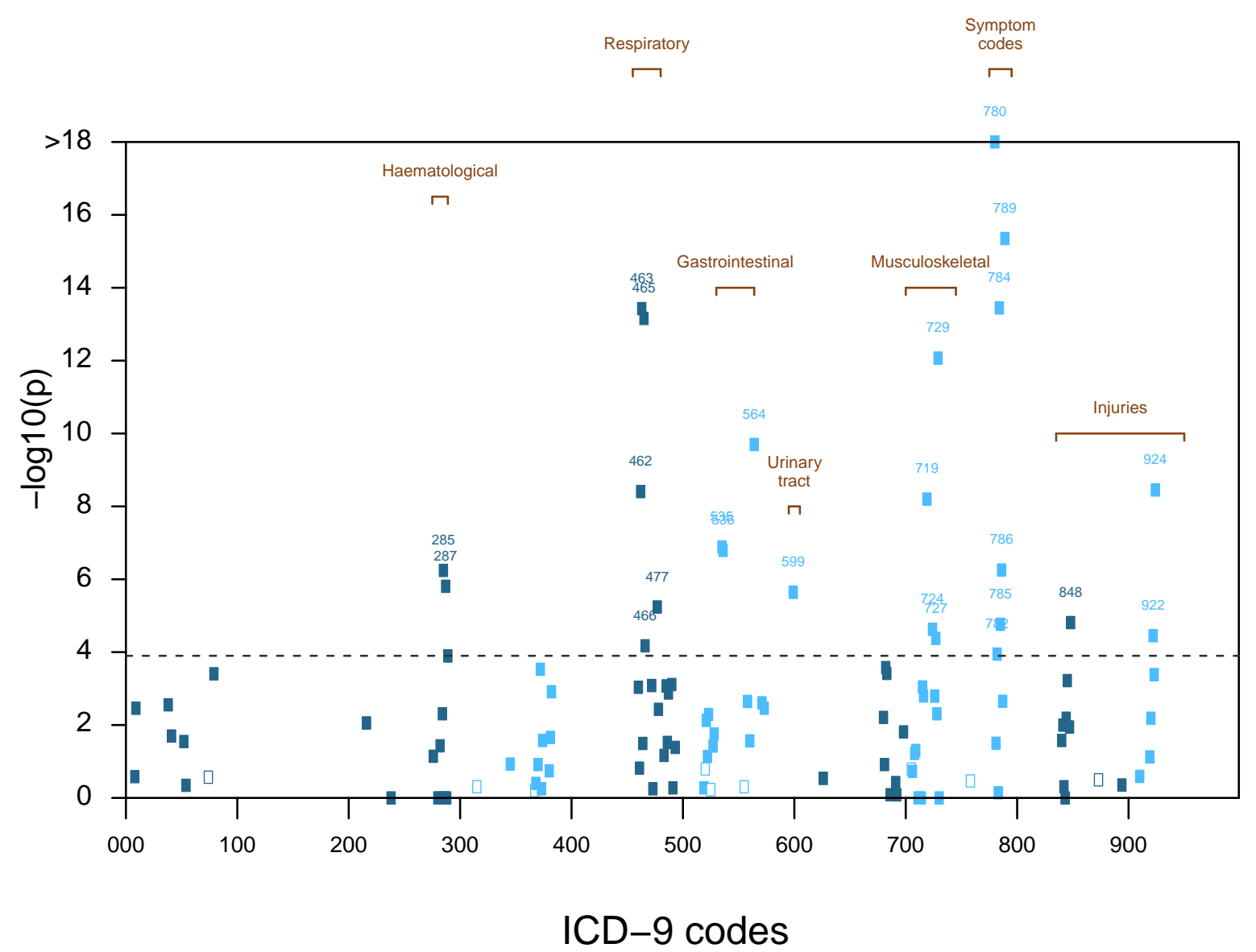

\section{ICD-9}

\section{Description}

Other and unspecified anaemias

Purpura and other haemorrhagic conditions

Acute pharyngitis

Acute tonsillitis

Acute upper respiratory infections of multiple or unspecified sites

Acute bronchitis and bronchiolitis

Allergic rhinitis

Gastritis and duodenitis

Disorders of function of stomach

Functional digestive disorders, not elsewhere classified

Other disorders of urethra and urinary tract

Other and unspecified disorder of joint

Other and unspecified disorders of back

Other disorders of synovium, tendon and bursa

Other disorders of soft tissues

General symptoms

Symptoms involving skin and other integumentary tissue

Symptoms involving head and neck

Symptoms involving cardiovascular system

Symptoms involving respiratory system and other chest symptoms Other symptoms involving abdomen and pelvis

Other and ill-defined sprains and strains

Contusion of trunk

Contusion of lower limb and of other and unspecified sites

\begin{tabular}{ll} 
Cases & \\
\hline $\begin{array}{l}1-180 \\
\text { days }\end{array}$ & $\begin{array}{l}181-360 \\
\text { days }\end{array}$
\end{tabular}

$\begin{array}{lll}165 & 2 & 6.2\end{array}$

$\begin{array}{lll}70 & 3 & 5.8\end{array}$

$344 \quad 230 \quad 8.4$

$459 \quad 283 \quad 13.4$

$\begin{array}{lll}1116 & 939 & 13.2\end{array}$

$613 \quad 526 \quad 4.2$

$213 \quad 141 \quad 5.2$

$\begin{array}{lll}180 & 95 & 6.9\end{array}$

$\begin{array}{lll}177 & 98 & 6.8\end{array}$

$\begin{array}{lll}211 & 111 & 9.7\end{array}$

$\begin{array}{lll}66 & 19 & 5.6\end{array}$

$\begin{array}{lll}71 & 8 & 8.2\end{array}$

$\begin{array}{lll}39 & 4 & 4.6\end{array}$

$\begin{array}{lll}41 & 2 & 4.4\end{array}$

$\begin{array}{lll}113 & 17 & 12.1\end{array}$

$\begin{array}{lll}367 & 148 \quad>18\end{array}$

$\begin{array}{lll}33 & 5 & 3.9\end{array}$

$\begin{array}{lll}157 & 48 & 13.4\end{array}$

$\begin{array}{lll}44 & 10 & 4.8\end{array}$

$\begin{array}{lll}170 & 100 & 6.3\end{array}$

$232 \quad 90 \quad 15.4$

$\begin{array}{lll}45 & 9 & 4.8\end{array}$

$\begin{array}{lll}38 & 5 & 4.5\end{array}$

$\begin{array}{lll}86 & 18 & 8.5\end{array}$ 


\section{Lymphoid Leukaemia}

\begin{tabular}{|c|c|c|c|c|c|c|c|}
\hline & $\begin{array}{c}\text { Months before the } \\
\text { date of leukaemia } \\
\text { diagnosis }\end{array}$ & $\%$ with presentation & $\begin{array}{l}\text { Odds ratios and } 95 \% \text { group } \\
\text { and time-specific confidence } \\
\text { intervals }\end{array}$ & & $\begin{array}{c}\text { Months before the } \\
\text { date of leukaemia } \\
\text { diagnosis }\end{array}$ & $\%$ with presentation & $\begin{array}{l}\text { Odds ratios and } 95 \% \text { group } \\
\text { and time-specific confidence } \\
\text { intervals }\end{array}$ \\
\hline \multirow{12}{*}{ Controls } & 1 & $57.3 \%$ & $0.95[0.92-0.97]$ & Cases & 1 & $92.5 \%$ & $9.47[7.49-11.99]$ \\
\hline & 2 & $57.0 \%$ & $0.94[0.91-0.96$ ] & & 2 & $68.3 \%$ & $1.52[1.33-1.74]$ \\
\hline & 3 & $57.1 \%$ & $0.94[0.91-0.97]$ & & 3 & $60.7 \%$ & $1.06[0.93-1.21]$ \\
\hline & 4 & $57.0 \%$ & $0.94[0.91-0.96]$ & & 4 & $58.2 \%$ & $0.95[0.84-1.08]$ \\
\hline & 5 & $57.3 \%$ & $0.95[0.92-0.97]$ & & 5 & $59.0 \%$ & $0.99[0.87-1.12$ ] \\
\hline & 6 & $56.9 \%$ & $0.93[0.91-0.96]$ & & 6 & $56.3 \%$ & $0.87[0.77-0.99]$ \\
\hline & 7 & $57.2 \%$ & $0.94[0.92-0.97]$ & & 7 & $57.1 \%$ & $0.90[0.80-1.03]$ \\
\hline & 8 & $57.5 \%$ & $0.96[0.93-0.98]$ & & 8 & $56.4 \%$ & $0.88[0.77-1.00]$ \\
\hline & 9 & $57.8 \%$ & $0.97[0.94-1.00]$ & & 9 & $58.2 \%$ & $0.95[0.84-1.08]$ \\
\hline & 10 & $58.2 \%$ & $0.99[0.96-1.01]$ & & 10 & $56.5 \%$ & $0.88[0.78-1.00]$ \\
\hline & 11 & $58.4 \%$ & 0.99 [ $0.97-1.02$ ] & & 11 & $59.1 \%$ & 0.99 [ $0.87-1.13$ ] \\
\hline & 12 & $58.5 \%$ & $1.00[0.97-1.03]$ & & 12 & $58.8 \%$ & $0.98[0.86-1.11]$ \\
\hline
\end{tabular}

Table: Numbers corresponding to Figure 1

Lymphoid leukaemia 


\section{Myeloid Leukaemia}

\begin{tabular}{|c|c|c|c|c|c|c|c|}
\hline & $\begin{array}{c}\text { Months before the } \\
\text { date of leukaemia } \\
\text { diagnosis }\end{array}$ & $\%$ with presentation & $\begin{array}{l}\text { Odds ratios and 95\% group } \\
\text { and time-specific confidence } \\
\text { intervals }\end{array}$ & & $\begin{array}{c}\text { Months before the } \\
\text { date of leukaemia } \\
\text { diagnosis }\end{array}$ & $\%$ with presentation & $\begin{array}{l}\text { Odds ratios and } 95 \% \text { group } \\
\text { and time-specific confidence } \\
\text { intervals }\end{array}$ \\
\hline \multirow[t]{12}{*}{ Controls } & 1 & $48.9 \%$ & $0.91[0.87-0.96]$ & Cases & 1 & $90.1 \%$ & $9.39[6.52-13.51]$ \\
\hline & 2 & $49.8 \%$ & $0.95[0.91-1.00]$ & & 2 & $65.3 \%$ & $1.80[1.42-2.27]$ \\
\hline & 3 & $49.7 \%$ & $0.95[0.90-0.99]$ & & 3 & $59.0 \%$ & $1.35[1.08-1.69]$ \\
\hline & 4 & $48.6 \%$ & $0.91[0.86-0.95]$ & & 4 & $58.7 \%$ & $1.33[1.06-1.67]$ \\
\hline & 5 & $48.9 \%$ & $0.92[0.87-0.96]$ & & 5 & $48.2 \%$ & $0.84[0.68-1.06]$ \\
\hline & 6 & $49.5 \%$ & $0.94[0.90-0.99$ ] & & 6 & $47.0 \%$ & $0.80[0.64-1.00]$ \\
\hline & 7 & $49.6 \%$ & $0.94[0.90-0.99$ ] & & 7 & $50.3 \%$ & $0.92[0.74-1.16]$ \\
\hline & 8 & $50.7 \%$ & 0.99 [ $0.94-1.04$ ] & & 8 & $53.0 \%$ & $1.04[0.83-1.30]$ \\
\hline & 9 & $50.3 \%$ & $0.97[0.93-1.02$ ] & & 9 & $48.8 \%$ & $0.87[0.69-1.08]$ \\
\hline & 10 & $52.2 \%$ & $1.05[1.00-1.10]$ & & 10 & $47.3 \%$ & $0.81[0.65-1.02]$ \\
\hline & 11 & $50.1 \%$ & $0.96[0.92-1.01]$ & & 11 & $49.1 \%$ & $0.88[0.70-1.10]$ \\
\hline & 12 & $51.0 \%$ & $1.00[0.96-1.05]$ & & 12 & $55.1 \%$ & $1.14[0.91-1.42]$ \\
\hline
\end{tabular}

Table: Numbers corresponding to Figure 1

Lymphoid leukaemia 


\section{Haematological Presentations}

\begin{tabular}{|c|c|c|c|c|c|c|c|}
\hline & $\begin{array}{c}\text { Months before the } \\
\text { date of leukaemia } \\
\text { diagnosis }\end{array}$ & $\begin{array}{c}\% \text { with } \\
\text { presentation }\end{array}$ & $\begin{array}{l}\text { Odds ratios and } 95 \% \text { group } \\
\text { and time-specific confidence } \\
\text { intervals }\end{array}$ & & $\begin{array}{c}\text { Months before the } \\
\text { date of leukaemia } \\
\text { diagnosis }\end{array}$ & $\begin{array}{c}\% \text { with } \\
\text { presentation }\end{array}$ & $\begin{array}{l}\text { Odds ratios and } 95 \% \text { group } \\
\text { and time-specific confidence } \\
\text { intervals }\end{array}$ \\
\hline \multirow[t]{12}{*}{ Controls } & 1 & $0.1 \%$ & $0.96[0.66-1.39]$ & Cases & 1 & $17.3 \%$ & $291.94[239.13-356.41]$ \\
\hline & 2 & $<0.1 \%$ & $0.69[0.42-1.14$ ] & & 2 & $2.4 \%$ & 26.29 [ $17.38-39.76$ ] \\
\hline & 3 & $0.1 \%$ & $1.35[0.95-1.93]$ & & 3 & $1.2 \%$ & 11.95 [ $6.67-21.40$ ] \\
\hline & 4 & $0.1 \%$ & $1.26[0.87-1.82]$ & & 4 & $<1 \%$ & $4.82[1.98-11.72]$ \\
\hline & 5 & $0.1 \%$ & $1.18[0.80-1.72]$ & & 5 & $<1 \%$ & $3.84[1.42-10.33$ ] \\
\hline & 6 & $0.1 \%$ & $1.26[0.87-1.82]$ & & 6 & $<1 \%$ & $0.94[0.13-6.74]$ \\
\hline & 7 & $0.1 \%$ & $1.13[0.77-1.67]$ & & 7 & $<1 \%$ & $0.94[0.13-6.74]$ \\
\hline & 8 & $0.1 \%$ & $1.09[0.73-1.62]$ & & 8 & 0 & no case \\
\hline & 9 & $0.1 \%$ & $1.09[0.73-1.62]$ & & 9 & $<1 \%$ & $0.94[0.13-6.74]$ \\
\hline & 10 & $0.1 \%$ & $1.09[0.73-1.62]$ & & 10 & $<1 \%$ & $0.94[0.13-6.74]$ \\
\hline & 11 & $0.1 \%$ & $1.13[0.77-1.67]$ & & 11 & $<1 \%$ & $0.94[0.13-6.74]$ \\
\hline & 12 & $0.1 \%$ & $1.00[0.69-1.45]$ & & 12 & $<1 \%$ & $0.94[0.13-6.74]$ \\
\hline
\end{tabular}

Exact percentages are not shown $<1 \%$ among cases and $<0.1 \%$ among controls to comply with data regulations

Table: Numbers corresponding to Figure 2

Lymphoid leukaemia 


\section{Respiratory presentations}

\begin{tabular}{|c|c|c|c|c|c|c|c|}
\hline & $\begin{array}{c}\text { Months before the } \\
\text { date of leukaemia } \\
\text { diagnosis }\end{array}$ & $\begin{array}{c}\% \text { with } \\
\text { presentation }\end{array}$ & $\begin{array}{c}\text { Odds ratios and } 95 \% \text { group } \\
\text { and time-specific confidence } \\
\text { intervals }\end{array}$ & & $\begin{array}{c}\text { Months before the } \\
\text { date of leukaemia } \\
\text { diagnosis }\end{array}$ & $\begin{array}{c}\% \text { with } \\
\text { presentation }\end{array}$ & $\begin{array}{c}\text { Odds ratios and } 95 \% \text { group } \\
\text { and time-specific confidence } \\
\text { intervals }\end{array}$ \\
\hline \multirow[t]{12}{*}{ Controls } & 1 & $42.4 \%$ & $0.89[0.87-0.92]$ & Cases & 1 & $75.1 \%$ & $4.17[3.59-4.84]$ \\
\hline & 2 & $41.9 \%$ & $0.88[0.85-0.90]$ & & 2 & $50.8 \%$ & $1.26[1.10-1.43]$ \\
\hline & 3 & $42.3 \%$ & $0.89[0.87-0.92]$ & & 3 & $43.6 \%$ & $0.91[0.80-1.04]$ \\
\hline & 4 & $42.6 \%$ & $0.90[0.88-0.93]$ & & 4 & $43.7 \%$ & $0.91[0.80-1.04]$ \\
\hline & 5 & $42.2 \%$ & $0.89[0.86-0.92]$ & & 5 & $43.1 \%$ & $0.89[0.78-1.01]$ \\
\hline & 6 & $42.0 \%$ & $0.88[0.86-0.91]$ & & 6 & $42.1 \%$ & $0.85[0.75-0.97]$ \\
\hline & 7 & $42.5 \%$ & $0.90[0.88-0.93]$ & & 7 & $41.6 \%$ & $0.83[0.73-0.94]$ \\
\hline & 8 & $43.3 \%$ & $0.93[0.91-0.96]$ & & 8 & $40.9 \%$ & $0.80[0.70-0.92]$ \\
\hline & 9 & $43.7 \%$ & $0.95[0.92-0.98]$ & & 9 & $42.0 \%$ & $0.84[0.74-0.96]$ \\
\hline & 10 & $44.3 \%$ & $0.98[0.95-1.01]$ & & 10 & $42.6 \%$ & $0.87[0.76-0.99]$ \\
\hline & 11 & $44.4 \%$ & $0.98[0.95-1.01]$ & & 11 & $44.1 \%$ & $0.93[0.82-1.06]$ \\
\hline & 12 & $44.8 \%$ & $1.00[0.97-1.03]$ & & 12 & $43.3 \%$ & $0.90[0.79-1.02]$ \\
\hline
\end{tabular}

Exact percentages are not shown $<1 \%$ among cases and $<0.1 \%$ among controls to comply with data regulations

Table: Numbers corresponding to Figure 2

\section{Lymphoid leukaemia}




\section{Gastrointestinal presentations}

\begin{tabular}{|c|c|c|c|c|c|c|c|}
\hline & $\begin{array}{l}\text { Months before the } \\
\text { date of leukaemia } \\
\text { diagnosis }\end{array}$ & $\begin{array}{c}\% \text { with } \\
\text { presentation }\end{array}$ & $\begin{array}{l}\text { Odds ratios and } 95 \% \text { group } \\
\text { and time-specific confidence } \\
\text { intervals }\end{array}$ & & $\begin{array}{l}\text { Months before the } \\
\text { date of leukaemia } \\
\text { diagnosis }\end{array}$ & $\begin{array}{c}\% \text { with } \\
\text { presentation }\end{array}$ & $\begin{array}{l}\text { Odds ratios and } 95 \% \text { group } \\
\text { and time-specific confidence } \\
\text { intervals }\end{array}$ \\
\hline \multirow[t]{12}{*}{ Controls } & 1 & $4.0 \%$ & $0.89[0.83-0.94]$ & Cases & 1 & $16.0 \%$ & $4.10[3.46-4.87]$ \\
\hline & 2 & $4.0 \%$ & 0.89 [ $0.84-0.96$ ] & & 2 & $8.0 \%$ & $1.82[1.45-2.29]$ \\
\hline & 3 & $4.1 \%$ & $0.92[0.86-0.99]$ & & 3 & $6.0 \%$ & $1.34[1.03-1.74]$ \\
\hline & 4 & $4.2 \%$ & $0.93[0.87-1.00]$ & & 4 & $4.9 \%$ & $1.06[0.80-1.41]$ \\
\hline & 5 & $4.1 \%$ & $0.91[0.85-0.98]$ & & 5 & $4.9 \%$ & $1.06[0.80-1.41]$ \\
\hline & 6 & $4.1 \%$ & $0.92[0.86-0.98]$ & & 6 & $4.5 \%$ & $0.97[0.72-1.31]$ \\
\hline & 7 & $4.3 \%$ & 0.97 [ $0.91-1.04$ ] & & 7 & $4.4 \%$ & $0.95[0.70-1.28]$ \\
\hline & 8 & $4.3 \%$ & $0.96[0.90-1.03]$ & & 8 & $4.3 \%$ & $0.93[0.68-1.26]$ \\
\hline & 9 & $4.1 \%$ & $0.92[0.86-0.98]$ & & 9 & $3.8 \%$ & $0.82[0.59-1.13]$ \\
\hline & 10 & $4.2 \%$ & $0.94[0.88-1.01]$ & & 10 & $4.7 \%$ & $1.02[0.76-1.36]$ \\
\hline & 11 & $4.3 \%$ & $0.97[0.91-1.04]$ & & 11 & $3.8 \%$ & $0.82[0.59-1.13]$ \\
\hline & 12 & $4.5 \%$ & $1.00[0.94-1.06]$ & & 12 & $4.2 \%$ & $0.90[0.67-1.23]$ \\
\hline
\end{tabular}

Exact percentages are not shown $<1 \%$ among cases and $<0.1 \%$ among controls to comply with data regulations

Table: Numbers corresponding to Figure 2

Lymphoid leukaemia 


\section{Urinary tract presentations}

\begin{tabular}{|c|c|c|c|c|c|c|c|}
\hline & $\begin{array}{c}\text { Months before the } \\
\text { date of leukaemia } \\
\text { diagnosis }\end{array}$ & $\begin{array}{c}\% \text { with } \\
\text { presentation }\end{array}$ & $\begin{array}{c}\text { Odds ratios and } 95 \% \text { group } \\
\text { and time-specific confidence } \\
\text { intervals }\end{array}$ & & $\begin{array}{c}\text { Months before the } \\
\text { date of leukaemia } \\
\text { diagnosis }\end{array}$ & $\begin{array}{c}\% \text { with } \\
\text { presentation }\end{array}$ & $\begin{array}{c}\text { Odds ratios and } 95 \% \text { group } \\
\text { and time-specific confidence } \\
\text { intervals }\end{array}$ \\
\hline \multirow[t]{12}{*}{ Controls } & 1 & $0.3 \%$ & $0.89[0.73-1.07]$ & Cases & 1 & $3.5 \%$ & $10.01[7.12-14.07]$ \\
\hline & 2 & $0.4 \%$ & $0.99[0.79-1.24]$ & & 2 & $1.3 \%$ & $3.45[1.99-5.99]$ \\
\hline & 3 & $0.4 \%$ & $0.99[0.79-1.24]$ & & 3 & $<1 \%$ & $1.83[0.87-3.87]$ \\
\hline & 4 & $0.4 \%$ & $1.13[0.91-1.39]$ & & 4 & $<1 \%$ & $1.30[0.54-3.15]$ \\
\hline & 5 & $0.4 \%$ & $1.01[0.81-1.26]$ & & 5 & $<1 \%$ & $1.04[0.39-2.79]$ \\
\hline & 6 & $0.3 \%$ & $0.82[0.65-1.05]$ & & 6 & $<1 \%$ & $0.78[0.25-2.43]$ \\
\hline & 7 & $0.3 \%$ & $0.82[0.65-1.05]$ & & 7 & $<1 \%$ & $0.52[0.13-2.08]$ \\
\hline & 8 & $0.3 \%$ & $0.94[0.74-1.18]$ & & 8 & $<1 \%$ & $0.52[0.13-2.08]$ \\
\hline & 9 & $0.3 \%$ & $0.87[0.69-1.11]$ & & 9 & $<1 \%$ & $1.57[0.70-3.51]$ \\
\hline & 10 & $0.3 \%$ & $0.90[0.71-1.14]$ & & 10 & 0 & no case \\
\hline & 11 & $0.4 \%$ & $1.04[0.83-1.29]$ & & 11 & 0 & no case \\
\hline & 12 & $0.4 \%$ & $1.00[0.83-1.21]$ & & 12 & $<1 \%$ & $0.52[0.13-2.08]$ \\
\hline
\end{tabular}

Exact percentages are not shown $<1 \%$ among cases and $<0.1 \%$ among controls to comply with data regulations

Table: Numbers corresponding to Figure 2

\section{Lymphoid leukaemia}




\section{Musculoskeletal presentations}

\begin{tabular}{|c|c|c|c|c|c|c|c|}
\hline & $\begin{array}{l}\text { Months before the } \\
\text { date of leukaemia } \\
\text { diagnosis }\end{array}$ & $\begin{array}{c}\% \text { with } \\
\text { presentation }\end{array}$ & $\begin{array}{l}\text { Odds ratios and } 95 \% \text { group } \\
\text { and time-specific confidence } \\
\text { intervals }\end{array}$ & & $\begin{array}{l}\text { Months before the } \\
\text { date of leukaemia } \\
\text { diagnosis }\end{array}$ & $\begin{array}{c}\% \text { with } \\
\text { presentation }\end{array}$ & $\begin{array}{l}\text { Odds ratios and } 95 \% \text { group } \\
\text { and time-specific confidence } \\
\text { intervals }\end{array}$ \\
\hline \multirow[t]{12}{*}{ Controls } & 1 & $0.6 \%$ & $1.25[1.05-1.49]$ & Cases & 1 & $14.5 \%$ & $37.92[31.59-45.51]$ \\
\hline & 2 & $0.7 \%$ & $1.28[1.08-1.51]$ & & 2 & $5.3 \%$ & $11.55[8.73-15.28]$ \\
\hline & 3 & $0.7 \%$ & $1.33[1.13-1.57$ ] & & 3 & $3.3 \%$ & 7.01 [ 4.96 - 9.92 ] \\
\hline & 4 & $0.7 \%$ & $1.32[1.12-1.56]$ & & 4 & $1.4 \%$ & $2.78[1.64-4.73]$ \\
\hline & 5 & $0.6 \%$ & $1.20[1.01-1.42]$ & & 5 & $1.2 \%$ & $2.38[1.34-4.21]$ \\
\hline & 6 & $0.6 \%$ & $1.09[0.91-1.30]$ & & 6 & $<1 \%$ & $1.77[0.92-3.43]$ \\
\hline & 7 & $0.6 \%$ & 1.07 [ $0.90-1.28$ ] & & 7 & $<1 \%$ & $1.18[0.53-2.63]$ \\
\hline & 8 & $0.7 \%$ & $1.28[1.08-1.51]$ & & 8 & $<1 \%$ & $1.37[0.65-2.90]$ \\
\hline & 9 & $0.5 \%$ & $0.94[0.77-1.14]$ & & 9 & $<1 \%$ & $1.37[0.65-2.90]$ \\
\hline & 10 & $0.6 \%$ & $1.12[0.94-1.33]$ & & 10 & $<1 \%$ & $0.78[0.29-2.09]$ \\
\hline & 11 & $0.5 \%$ & $0.97[0.81-1.17]$ & & 11 & $<1 \%$ & $0.78[0.29-2.09]$ \\
\hline & 12 & $0.5 \%$ & $1.00[0.84-1.19]$ & & 12 & $<1 \%$ & $0.98[0.41-2.36]$ \\
\hline
\end{tabular}

Exact percentages are not shown $<1 \%$ among cases and $<0.1 \%$ among controls to comply with data regulations

Table: Numbers corresponding to Figure 2

Lymphoid leukaemia 


\section{Injuries}

\begin{tabular}{|c|c|c|c|c|c|c|c|}
\hline & $\begin{array}{c}\text { Months before the } \\
\text { date of leukaemia } \\
\text { diagnosis }\end{array}$ & $\begin{array}{c}\% \text { with } \\
\text { presentation }\end{array}$ & $\begin{array}{l}\text { Odds ratios and } 95 \% \text { group } \\
\text { and time-specific confidence } \\
\text { intervals }\end{array}$ & & $\begin{array}{c}\text { Months before the } \\
\text { date of leukaemia } \\
\text { diagnosis }\end{array}$ & $\begin{array}{c}\% \text { with } \\
\text { presentation }\end{array}$ & $\begin{array}{c}\text { Odds ratios and } 95 \% \text { group } \\
\text { and time-specific confidence } \\
\text { intervals }\end{array}$ \\
\hline \multirow[t]{12}{*}{ Controls } & 1 & $1.5 \%$ & $1.07[0.96-1.19]$ & Cases & 1 & $12.4 \%$ & $10.16[8.42-12.27]$ \\
\hline & 2 & $1.6 \%$ & $1.15[1.03-1.27]$ & & 2 & $6.2 \%$ & $4.71[3.65-6.08]$ \\
\hline & 3 & $1.5 \%$ & $1.07[0.96-1.19]$ & & 3 & $4.5 \%$ & $3.31[2.46-4.46]$ \\
\hline & 4 & $1.5 \%$ & $1.08[0.97-1.20]$ & & 4 & $2.5 \%$ & $1.82[1.23-2.70]$ \\
\hline & 5 & $1.6 \%$ & $1.12[1.01-1.25]$ & & 5 & $2.6 \%$ & $1.90[1.29-2.78]$ \\
\hline & 6 & $1.5 \%$ & $1.08[0.97-1.21]$ & & 6 & $1.9 \%$ & $1.32[0.84-2.08]$ \\
\hline & 7 & $1.5 \%$ & $1.02[0.92-1.14]$ & & 7 & $1.6 \%$ & $1.11[0.68-1.82]$ \\
\hline & 8 & $1.6 \%$ & $1.09[0.98-1.22]$ & & 8 & $2.2 \%$ & $1.61[1.06-2.43]$ \\
\hline & 9 & $1.5 \%$ & $1.06[0.95-1.18]$ & & 9 & $2.0 \%$ & $1.39[0.89-2.17]$ \\
\hline & 10 & $1.6 \%$ & $1.12[1.01-1.25]$ & & 10 & $1.9 \%$ & $1.32[0.84-2.08]$ \\
\hline & 11 & $1.4 \%$ & 0.98 [ $0.87-1.09]$ & & 11 & $1.2 \%$ & $0.83[0.47-1.46]$ \\
\hline & 12 & $1.4 \%$ & $1.00[0.90-1.11]$ & & 12 & $1.1 \%$ & $0.76[0.42-1.37]$ \\
\hline
\end{tabular}

Exact percentages are not shown $<1 \%$ among cases and $<0.1 \%$ among controls to comply with data regulations

Table: Numbers corresponding to Figure 2

Lymphoid leukaemia

Appendix p11 


\section{Haematological Presentations}

\begin{tabular}{|c|c|c|c|c|c|c|c|}
\hline & $\begin{array}{c}\text { Months before the } \\
\text { date of leukaemia } \\
\text { diagnosis }\end{array}$ & $\%$ with presentation & $\begin{array}{l}\text { Odds ratios and } 95 \% \text { group } \\
\text { and time-specific confidence } \\
\text { intervals }\end{array}$ & & $\begin{array}{l}\text { Months before the } \\
\text { date of leukaemia } \\
\text { diagnosis }\end{array}$ & $\%$ with presentation & $\begin{array}{l}\text { Odds ratios and } 95 \% \text { group } \\
\text { and time-specific confidence } \\
\text { intervals }\end{array}$ \\
\hline \multirow[t]{12}{*}{ Controls } & 1 & $<0.1 \%$ & $1.00[0.47-2.14]$ & Cases & 1 & $15.6 \%$ & $375.75[257.28-548.76]$ \\
\hline & 2 & $0.1 \%$ & $1.80[0.92-3.52]$ & & 2 & $4.5 \%$ & $76.86[43.78-134.93$ ] \\
\hline & 3 & $0.1 \%$ & $1.80[0.92-3.52]$ & & 3 & $1.5 \%$ & $22.96[9.22-57.17]$ \\
\hline & 4 & $<0.1 \%$ & $1.00[0.41-2.43]$ & & 4 & $1.2 \%$ & 18.15 [ $6.59-49.96$ ] \\
\hline & 5 & $<0.1 \%$ & $1.40[0.66-2.98]$ & & 5 & $<1 \%$ & $13.45[4.21-42.91]$ \\
\hline & 6 & $<0.1 \%$ & $1.00[0.41-2.43]$ & & 6 & $<1 \%$ & $8.85[2.16-36.26]$ \\
\hline & 7 & $<0.1 \%$ & $1.40[0.66-2.98]$ & & 7 & $<1 \%$ & $8.85[2.16-36.26]$ \\
\hline & 8 & $<0.1 \%$ & $0.60[0.19-1.88]$ & & 8 & $<1 \%$ & $4.37[0.61-31.57]$ \\
\hline & 9 & $<0.1 \%$ & $0.80[0.30-2.15]$ & & 9 & $<1 \%$ & $4.37[0.61-31.57]$ \\
\hline & 10 & $<0.1 \%$ & $1.40[0.66-2.98]$ & & 10 & $<1 \%$ & $8.85[2.16-36.26]$ \\
\hline & 11 & $<0.1 \%$ & $1.40[0.66-2.98]$ & & 11 & 0 & no case \\
\hline & 12 & $<0.1 \%$ & $1.00[0.47-2.14]$ & & 12 & 0 & no case \\
\hline
\end{tabular}

Exact percentages are not shown $<1 \%$ among cases and $<0.1 \%$ among controls to comply with data regulations

Table: Numbers corresponding to Figure 2

Myeloid leukaemia 


\section{Respiratory presentations}

\begin{tabular}{|c|c|c|c|c|c|c|c|}
\hline & $\begin{array}{c}\text { Months before the } \\
\text { date of leukaemia } \\
\text { diagnosis }\end{array}$ & $\%$ with presentation & $\begin{array}{l}\text { Odds ratios and } 95 \% \text { group } \\
\text { and time-specific confidence } \\
\text { intervals }\end{array}$ & & $\begin{array}{c}\text { Months before the } \\
\text { date of leukaemia } \\
\text { diagnosis }\end{array}$ & $\%$ with presentation & $\begin{array}{l}\text { Odds ratios and } 95 \% \text { group } \\
\text { and time-specific confidence } \\
\text { intervals }\end{array}$ \\
\hline \multirow[t]{12}{*}{ Controls } & 1 & $32.7 \%$ & $0.91[0.86-0.95]$ & Cases & 1 & $69.2 \%$ & $4.70[3.68-5.99]$ \\
\hline & 2 & $33.0 \%$ & $0.92[0.87-0.97$ ] & & 2 & $47.3 \%$ & $1.69[1.35-2.13]$ \\
\hline & 3 & $33.0 \%$ & $0.92[0.88-0.97]$ & & 3 & $40.1 \%$ & $1.22[0.97-1.54]$ \\
\hline & 4 & $31.6 \%$ & $0.86[0.82-0.90]$ & & 4 & $41.3 \%$ & $1.29[1.02-1.62]$ \\
\hline & 5 & $32.0 \%$ & $0.88[0.83-0.92]$ & & 5 & $33.5 \%$ & $0.89[0.70-1.13]$ \\
\hline & 6 & $33.0 \%$ & $0.92[0.87-0.97]$ & & 6 & $31.4 \%$ & $0.80[0.62-1.02]$ \\
\hline & 7 & $33.1 \%$ & $0.93[0.88-0.98]$ & & 7 & $35.0 \%$ & $0.96[0.75-1.21]$ \\
\hline & 8 & $34.4 \%$ & $0.99[0.94-1.04]$ & & 8 & $34.7 \%$ & $0.94[0.74-1.20]$ \\
\hline & 9 & $34.5 \%$ & $0.99[0.94-1.04]$ & & 9 & $35.0 \%$ & $0.96[0.75-1.21]$ \\
\hline & 10 & $35.1 \%$ & $1.02[0.97-1.08]$ & & 10 & $31.1 \%$ & $0.78[0.61-1.00]$ \\
\hline & 11 & $34.1 \%$ & $0.97[0.93-1.02]$ & & 11 & $37.7 \%$ & $1.09[0.86-1.38]$ \\
\hline & 12 & $34.6 \%$ & $1.00[0.95-1.05]$ & & 12 & $37.4 \%$ & $1.07[0.85-1.36]$ \\
\hline
\end{tabular}

Exact percentages are not shown $<1 \%$ among cases and $<0.1 \%$ among controls to comply with data regulations

Table: Numbers corresponding to Figure 2

Myeloid leukaemia

Appendix p13 
Gastrointestinal presentations

\begin{tabular}{|c|c|c|c|c|c|c|c|}
\hline & $\begin{array}{c}\text { Months before the } \\
\text { date of leukaemia } \\
\text { diagnosis }\end{array}$ & $\%$ with presentation & $\begin{array}{l}\text { Odds ratios and } 95 \% \text { group } \\
\text { and time-specific confidence } \\
\text { intervals }\end{array}$ & & $\begin{array}{c}\text { Months before the } \\
\text { date of leukaemia } \\
\text { diagnosis }\end{array}$ & $\%$ with presentation & $\begin{array}{l}\text { Odds ratios and } 95 \% \text { group } \\
\text { and time-specific confidence } \\
\text { intervals }\end{array}$ \\
\hline \multirow[t]{12}{*}{ Controls } & 1 & $3.2 \%$ & $0.95[0.84-1.07]$ & Cases & 1 & $14.7 \%$ & $5.01[3.68-6.84]$ \\
\hline & 2 & $3.3 \%$ & $0.98[0.86-1.11]$ & & 2 & $4.2 \%$ & $1.23[0.72-2.10]$ \\
\hline & 3 & $3.1 \%$ & $0.92[0.81-1.05]$ & & 3 & $6.9 \%$ & $2.10[1.36-3.22]$ \\
\hline & 4 & $3.0 \%$ & $0.90[0.79-1.03]$ & & 4 & $4.8 \%$ & $1.41[0.85-2.35]$ \\
\hline & 5 & $3.1 \%$ & $0.93[0.81-1.06$ ] & & 5 & $3.9 \%$ & $1.13[0.65-1.98]$ \\
\hline & 6 & $3.2 \%$ & $0.96[0.84-1.10]$ & & 6 & $5.1 \%$ & $1.51[0.92-2.47]$ \\
\hline & 7 & $2.9 \%$ & $0.87[0.76-1.00$ ] & & 7 & $3.9 \%$ & $1.13[0.65-1.98]$ \\
\hline & 8 & $3.1 \%$ & $0.92[0.81-1.06]$ & & 8 & $3.3 \%$ & $0.95[0.52-1.74]$ \\
\hline & 9 & $3.2 \%$ & $0.97[0.85-1.10]$ & & 9 & $3.6 \%$ & $1.04[0.58-1.86]$ \\
\hline & 10 & $3.4 \%$ & $1.01[0.89-1.15$ ] & & 10 & $3.9 \%$ & $1.13[0.65-1.98]$ \\
\hline & 11 & $3.1 \%$ & $0.93[0.82-1.06]$ & & 11 & $3.0 \%$ & $0.86[0.46-1.62]$ \\
\hline & 12 & $3.3 \%$ & $1.00[0.89-1.13]$ & & 12 & $5.7 \%$ & $1.70[1.07-2.72]$ \\
\hline
\end{tabular}

Exact percentages are not shown $<1 \%$ among cases and $<0.1 \%$ among controls to comply with data regulations

Table: Numbers corresponding to Figure 2

Myeloid leukaemia

Appendix p14 


\section{Urinary tract presentations}

\begin{tabular}{|c|c|c|c|c|c|c|c|}
\hline & $\begin{array}{c}\text { Months before the } \\
\text { date of leukaemia } \\
\text { diagnosis }\end{array}$ & $\%$ with presentation & $\begin{array}{l}\text { Odds ratios and } 95 \% \text { group } \\
\text { and time-specific confidence } \\
\text { intervals }\end{array}$ & & $\begin{array}{c}\text { Months before the } \\
\text { date of leukaemia } \\
\text { diagnosis }\end{array}$ & $\%$ with presentation & $\begin{array}{l}\text { Odds ratios and } 95 \% \text { group } \\
\text { and time-specific confidence } \\
\text { intervals }\end{array}$ \\
\hline \multirow[t]{12}{*}{ Controls } & 1 & $0.2 \%$ & $0.54[0.39-0.75]$ & Cases & 1 & $2.4 \%$ & $7.37[3.61-15.07$ ] \\
\hline & 2 & $0.1 \%$ & $0.33[0.16-0.67]$ & & 2 & $<1 \%$ & $1.77[0.44-7.17$ ] \\
\hline & 3 & $0.2 \%$ & $0.62[0.37-1.04]$ & & 3 & 0 & no case \\
\hline & 4 & $0.2 \%$ & 0.67 [ $0.40-1.09$ ] & & 4 & $<1 \%$ & $0.88[0.12-6.30]$ \\
\hline & 5 & $0.2 \%$ & $0.62[0.37-1.04]$ & & 5 & 0 & no case \\
\hline & 6 & $0.3 \%$ & $0.83[0.53-1.30]$ & & 6 & 0 & no case \\
\hline & 7 & $0.3 \%$ & $0.79[0.50-1.25]$ & & 7 & $<1 \%$ & $1.77[0.44-7.17]$ \\
\hline & 8 & $0.3 \%$ & $0.92[0.60-1.40]$ & & 8 & $<1 \%$ & $0.88[0.12-6.30]$ \\
\hline & 9 & $0.2 \%$ & $0.67[0.40-1.09$ ] & & 9 & $<1 \%$ & $1.77[0.44-7.17]$ \\
\hline & 10 & $0.3 \%$ & $0.83[0.53-1.30]$ & & 10 & $1.5 \%$ & $4.52[1.85-11.05]$ \\
\hline & 11 & $0.2 \%$ & $0.75[0.47-1.20]$ & & 11 & $<1 \%$ & $0.88[0.12-6.30]$ \\
\hline & 12 & $0.3 \%$ & $1.00[0.72-1.39]$ & & 12 & $<1 \%$ & $0.88[0.12-6.30]$ \\
\hline
\end{tabular}

Exact percentages are not shown $<1 \%$ among cases and $<0.1 \%$ among controls to comply with data regulations

Table: Numbers corresponding to Figure 2

Myeloid leukaemia 


\section{Musculoskeletal presentations}

\begin{tabular}{|c|c|c|c|c|c|c|c|}
\hline & $\begin{array}{c}\text { Months before the } \\
\text { date of leukaemia } \\
\text { diagnosis }\end{array}$ & $\%$ with presentation & $\begin{array}{l}\text { Odds ratios and } 95 \% \text { group } \\
\text { and time-specific confidence } \\
\text { intervals }\end{array}$ & & $\begin{array}{c}\text { Months before the } \\
\text { date of leukaemia } \\
\text { diagnosis }\end{array}$ & $\%$ with presentation & $\begin{array}{l}\text { Odds ratios and } 95 \% \text { group } \\
\text { and time-specific confidence } \\
\text { intervals }\end{array}$ \\
\hline \multirow[t]{12}{*}{ Controls } & 1 & $0.8 \%$ & $1.42[1.07-1.90]$ & Cases & 1 & $6.6 \%$ & $12.99[8.34-20.23]$ \\
\hline & 2 & $0.7 \%$ & $1.14[0.86-1.51]$ & & 2 & $3.0 \%$ & $5.53[2.93-10.46]$ \\
\hline & 3 & $0.8 \%$ & $1.35[1.04-1.76]$ & & 3 & $2.4 \%$ & $4.38[2.16-8.89]$ \\
\hline & 4 & $0.8 \%$ & $1.31[1.00-1.70]$ & & 4 & $1.5 \%$ & $2.69[1.11-6.54]$ \\
\hline & 5 & $0.7 \%$ & $1.26[0.96-1.65]$ & & 5 & $1.2 \%$ & $2.14[0.79-5.77]$ \\
\hline & 6 & $0.6 \%$ & $1.12[0.84-1.49]$ & & 6 & $<1 \%$ & $1.60[0.51-5.00]$ \\
\hline & 7 & $0.8 \%$ & $1.35[1.04-1.76$ ] & & 7 & $<1 \%$ & $1.06[0.26-4.27]$ \\
\hline & 8 & $0.8 \%$ & $1.31[1.00-1.70]$ & & 8 & $<1 \%$ & $1.06[0.26-4.27]$ \\
\hline & 9 & $0.8 \%$ & $1.31[1.00-1.70]$ & & 9 & $<1 \%$ & $1.06[0.26-4.27]$ \\
\hline & 10 & $0.8 \%$ & $1.38[1.06-1.78]$ & & 10 & $<1 \%$ & $1.06[0.26-4.27]$ \\
\hline & 11 & $0.6 \%$ & $1.07[0.80-1.43]$ & & 11 & $1.2 \%$ & $2.14[0.79-5.77]$ \\
\hline & 12 & $0.6 \%$ & $1.00[0.75-1.33]$ & & 12 & $<1 \%$ & $1.60[0.51-5.00]$ \\
\hline
\end{tabular}

Exact percentages are not shown $<1 \%$ among cases and $<0.1 \%$ among controls to comply with data regulations

Table: Numbers corresponding to Figure 2

Myeloid leukaemia 


\section{Injuries}

\begin{tabular}{|c|c|c|c|c|c|c|c|}
\hline & $\begin{array}{c}\text { Months before the } \\
\text { date of leukaemia } \\
\text { diagnosis }\end{array}$ & $\%$ with presentation & $\begin{array}{l}\text { Odds ratios and } 95 \% \text { group } \\
\text { and time-specific confidence } \\
\text { intervals }\end{array}$ & & $\begin{array}{c}\text { Months before the } \\
\text { date of leukaemia } \\
\text { diagnosis }\end{array}$ & $\%$ with presentation & $\begin{array}{c}\text { Odds ratios and } 95 \% \text { group } \\
\text { and time-specific confidence } \\
\text { intervals }\end{array}$ \\
\hline \multirow[t]{12}{*}{ Controls } & 1 & $1.6 \%$ & $0.95[0.80-1.13]$ & Cases & 1 & $5.1 \%$ & $3.17[1.94-5.18]$ \\
\hline & 2 & $1.8 \%$ & $1.09[0.92-1.29$ ] & & 2 & $3.6 \%$ & $2.19[1.23-3.91]$ \\
\hline & 3 & $1.9 \%$ & $1.10[0.93-1.30]$ & & 3 & $3.6 \%$ & $2.19[1.23-3.91]$ \\
\hline & 4 & $1.7 \%$ & 0.98 [ $0.82-1.17$ ] & & 4 & $2.4 \%$ & $1.44[0.71-2.91]$ \\
\hline & 5 & $1.8 \%$ & $1.06[0.89-1.26]$ & & 5 & $1.2 \%$ & $0.71[0.26-1.90]$ \\
\hline & 6 & $1.7 \%$ & $0.99[0.83-1.18]$ & & 6 & $2.4 \%$ & $1.44[0.71-2.91]$ \\
\hline & 7 & $1.7 \%$ & $1.01[0.85-1.20$ ] & & 7 & $1.5 \%$ & $0.89[0.37-2.15]$ \\
\hline & 8 & $1.6 \%$ & $0.97[0.81-1.16$ ] & & 8 & $1.5 \%$ & $0.89[0.37-2.15]$ \\
\hline & 9 & $1.8 \%$ & $1.06[0.89-1.26]$ & & 9 & $1.5 \%$ & $0.89[0.37-2.15]$ \\
\hline & 10 & $1.8 \%$ & $1.09[0.92-1.29]$ & & 10 & $1.2 \%$ & $0.71[0.26-1.90]$ \\
\hline & 11 & $1.5 \%$ & $0.89[0.74-1.07]$ & & 11 & $2.7 \%$ & $1.62[0.83-3.16]$ \\
\hline & 12 & $1.7 \%$ & $1.00[0.84-1.18]$ & & 12 & $3.0 \%$ & $1.81[0.96-3.41]$ \\
\hline
\end{tabular}

Exact percentages are not shown $<1 \%$ among cases and $<0.1 \%$ among controls to comply with data regulations

Table: Numbers corresponding to Figure 2

\section{Myeloid leukaemia}


STATA OUTPUT corresponding to REVIEWER \#2 MAJOR CONCERN \#1

Hixed-effects logistic regression
Group variable:

Integration method: maghenite

Log likelihood = -173997.67 $\begin{array}{llr}\text { Number of obs } & = & 27,200 \\ \text { Number of groups } & = & \mathbf{1 , 0 2 5}\end{array}$

Obs per group:

$\begin{array}{lr}\text { Min }= & 12 \\ \text { avg }= & \mathbf{2 6 8 . 5} \\ \max = & 372\end{array}$

Integration pts. =

7

Hald chi2(25) = 2520.90

Prob $>$ chi2 $=0.0000$

\begin{tabular}{|c|c|c|c|c|c|c|}
\hline x02_check & Coef. & Std. Err. & $z$ & $P>|z|$ & \multicolumn{2}{|c|}{ [95\% Conf. Interval] } \\
\hline $\begin{array}{cc}\text { cctype\# } \\
\text { timeback } \\
0 & 1 \\
0 & 2 \\
0 & 3 \\
0 & 4 \\
0 & 5 \\
0 & 6 \\
0 & 7 \\
0 & 8 \\
0 & 9 \\
0 & 10 \\
0 & 11 \\
1 & 1 \\
1 & 2 \\
1 & 3 \\
1 & 4 \\
1 & 5 \\
1 & 6 \\
1 & 7 \\
1 & 8 \\
1 & 9 \\
1 & 10 \\
1 & 11 \\
1 & 12\end{array}$ & 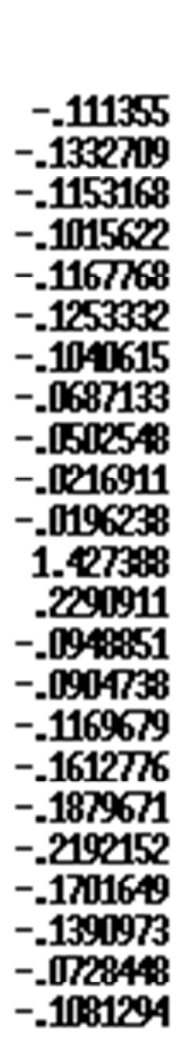 & 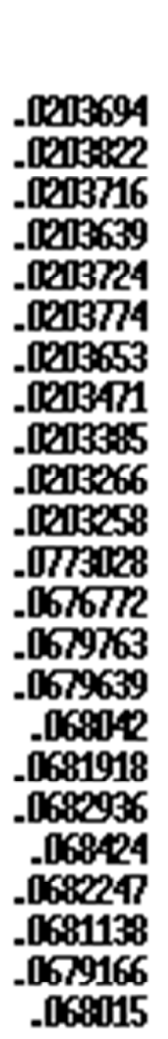 & $\begin{array}{r}-5.47 \\
-6.54 \\
-5.66 \\
-4.99 \\
-5.73 \\
-6.15 \\
-5.11 \\
-3.38 \\
-2.47 \\
-1.07 \\
-1.97 \\
18.46 \\
3.39 \\
-1.40 \\
-1.33 \\
-1.72 \\
-2.37 \\
-2.75 \\
-3.20 \\
-2.49 \\
-2.04 \\
-1.07 \\
-1.59\end{array}$ & $\begin{array}{l}\text { 0.000 } \\
0.000 \\
0.000 \\
0.000 \\
0.000 \\
0.000 \\
0.000 \\
0.001 \\
0.013 \\
0.286 \\
0.334 \\
0.000 \\
0.001 \\
0.163 \\
0.183 \\
0.086 \\
0.018 \\
0.016 \\
0.001 \\
0.013 \\
0.041 \\
0.283 \\
0.112\end{array}$ & 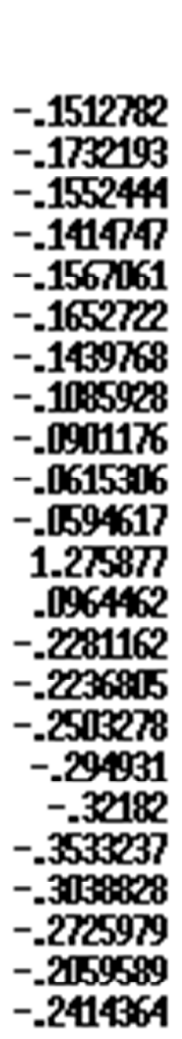 & 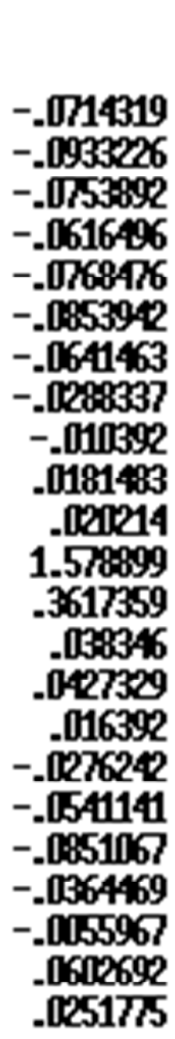 \\
\hline $\begin{array}{r}\text { cancer_agec } \\
5 \\
9\end{array}$ & $\begin{array}{l}-.2411917 \\
-1.205462\end{array}$ & $\begin{array}{r}.0212623 \\
.0277\end{array}$ & $\begin{array}{l}-11.34 \\
-43.41\end{array}$ & $\begin{array}{l}0.000 \\
0.000\end{array}$ & $\begin{array}{l}-.2028655 \\
-1.25969\end{array}$ & $\begin{array}{l}-.1995184 \\
-1.151034\end{array}$ \\
\hline _cons & .206274 & .019102 & 10.48 & 0.000 & .1866843 & .272575 \\
\hline $\begin{array}{l}\text { etnum } \\
\text { var(_cons) }\end{array}$ & .1140011 & .006616 & & & .1025417 & .1287502 \\
\hline
\end{tabular}

LR test vs. $\operatorname{logistic}$ nodel: chibar $2(01)=\mathbf{4 6 2 . 4 8} \quad$ Prob $>=$ chibar2 $=\mathbf{0 . 0 0 0 0}$ 